\title{
TECHNICAL REPORT SERIES
}

Science in trade disputes related to potential risks: comparative case studies

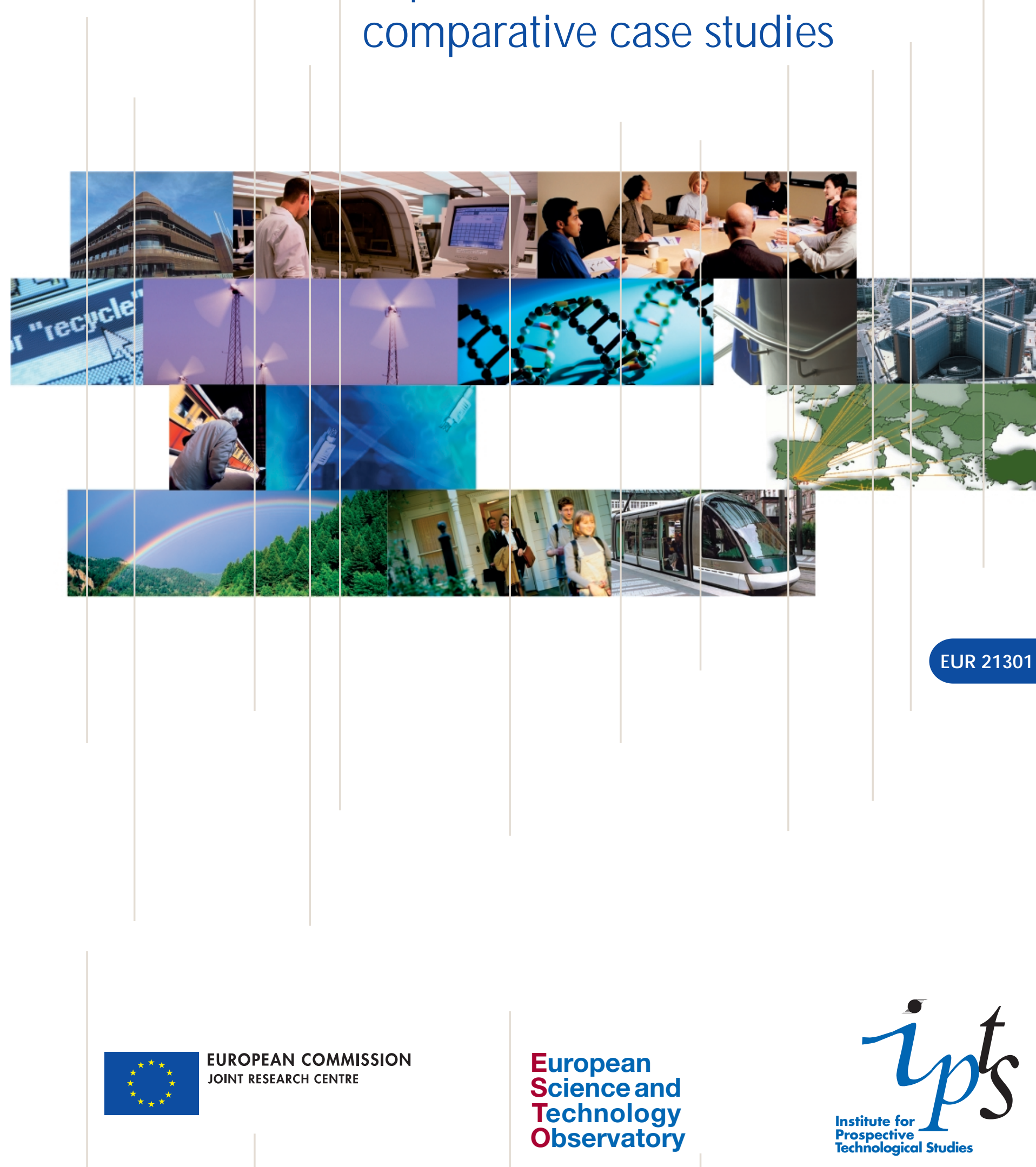




\section{European Commission}

Joint Research Centre (DG JRC)

Institute for Prospective Technological Studies

http://www.jrc.es

\section{Legal notice}

Neither the European Commission nor any person acting on behalf of the Commission is responsible for the use which might be made of the following information.

(c) European Communities, 2004

Reproduction is authorised provided the source is acknowledged. 


\section{About the JRC-IPTS}

The Joint Research Centre (JRC) is a Directorate General of the European Commission, staffed with approximately 2,100 people, coming in the vast majority from the 15 Member States of the European Union. The Brussels Support Services (including the office of the Director General and the Science Strategy Directorate) and seven Institutes located in five different countries compose the main organisational structure of the JRC (http//:www.jrc.org). The Institute for Prospective Technological Studies (IPTS) is one of the seven Institutes making up the JRC. The mission of the JRC is to provide customer-driven scientific and technical support for the conception, implementation and monitoring of EU policies.

The Institute for Prospective Technological Studies (IPTS) is one of the seven Institutes making up the JRC. It was established in Seville, Spain, in September 1994.

The mission of the IPTS is to provide prospective techno-economic analyses in support of the European policy-making process. IPTS' prime objectives are to monitor and analyse science and technology developments, their cross-sectoral impact, and their inter-relationship with the socioeconomic context and their implications for future policy development. IPTS operates international networks, pools the expertise of high level advisors, and presents information in a timely and synthetic fashion to policy makers (http//:www.jrc.es).

The IPTS is a unique public advisory body, independent from special national or commercial interests, closely associated with the EU policymaking process. In fact, most of the work undertaken by the IPTS is in response to direct requests from (or takes the form of long-term policy support on behalf of) the European Commission Directorate Generals, or European Parliament Committees. The IPTS also does work for Member States' governmental, academic or industrial organisations, though this represents a minor share of its total activities.

Although particular emphasis is placed on key Science and Technology fields, especially those that have a driving role and even the potential to reshape our society, important efforts are devoted to improving the understanding of the complex interactions between technology, economy and society. Indeed, the impact of technology on society and, conversely, the way technological development is driven by societal changes, are highly relevant themes within the European decision-making context.

The inter-disciplinary prospective approach adopted by the Institute is intended to provide European decision-makers with a deeper understanding of the emerging science and technology issues, and it complements the activities undertaken by other institutes of the Joint Research Centre.

The IPTS approach is to collect information about technological developments and their application in Europe and the world, analyse this information and transmit it in an accessible form to European decision-makers. This is implemented in the following sectors of activity:

- Technologies for Sustainable Development

- Life Sciences / Information and Communication Technologies

- Technology, Employment, Competitiveness and Society

- Futures project

In order to implement its mission, the Institute develops appropriate contacts, awareness and skills to anticipate and follow the agenda of the policy decision-makers. IPTS Staff is a mix of highly experienced engineers, scientists (life-, social- material- etc.) and economists. Cross-disciplinary experience is a necessary asset. The IPTS success is also based on its networking capabilities and the quality of its networks as enabling sources of relevant information. In fact, in addition to its own resources, the IPTS makes use of external Advisory Groups and operates a number of formal or informal networks. The most important is a Network of European Institutes (the European Science and Technology Observatory) working in similar areas. These networking activities enable the IPTS to draw on a large pool of available expertise, while allowing a continuous process of external peer-review of the in-house activities.

\section{About ESTO}

The European Science and Technology Observatory (ESTO) is a network of organisations operating as a virtual institute under the European Commission's - Joint Research Centre's (JRC's) Institute for Prospective Technological Studies (IPTS) - leadership and funding. The European Commission JRC-IPTS formally constituted, following a brief pilot period, the European Science and Technology Observatory (ESTO) in 1997. After a call for tender, the second formal contract for ESTO started on May $1^{\text {st }} 2001$ for a period of 5 years.

Today, ESTO is presently composed of a core of twenty European institutions, all with experience in the field of scientific and technological foresight, forecasting or assessment at the national level. These nineteen organisations have a formal obligation towards the IPTS and are the nucleus of a far larger network. Membership is being continuously reviewed and expanded with a view to match the evolving needs of the IPTS and to incorporate new competent organisations from both inside and outside of the EU. This includes the objective to broaden the operation of the ESTO network to include relevant partners from EU Candidate Countries. In line with the objective of supporting the JRC-IPTS work, ESTO aims at detecting, at an early stage, scientific or technological breakthroughs, trends and events of potential socio-economic importance, which may require action at a European decision-making level.

The ESTO core-competence therefore resides in prospective analysis and advice on S\&T changes relevant to EU society, economy and policy.

The main customers for these activities is the JRC-IPTS, and through it, the European policy-makers, in particular within the European Commission and Parliament. ESTO also recognises and addresses the role of a much wider community, such as policy-making circles in the Member States and decision-makers in both non-governmental organisations and industry.

ESTO members, therefore, share the responsibility of supplying the IPTS with up-to-date and high quality scientific and technological information drawn from all over the world, facilitated by the network's broad presence and linkages, including access to relevant knowledge within the JRC' Institutes.

Currently, ESTO is engaged in the following main activities:

A series of Specific Studies, These studies, usually consist in comparing the situation, practices and/or experiences in various member states, and can be of a different nature a) Anticipation/Prospective analysis, intended to act as a trigger for in-depth studies of European foresight nature, aiming at the identification and description of trends rather than static situations; b) Direct support of policies in preparation (ex-ante analysis); and c) Direct support of policies in action (ex-post analysis, anticipating future developments).

Implementation of Fast-Track actions to provide quick responses to specific S\&T assessment queries. On the other hand, they can precede or complement the above mentioned Specific Studies.

To produce input to Monitoring Prospective S\&T Activities that serves as a basis of experience and information for all other tasks.

ESTO develops a "Alert/Early Warning" function by means of Technology Watch/Thematic Platforms activities. These actions are putting ESTO and JRC-IPTS in the position to be able to provide rapid responses to specific requests from European decision-makers. 0Support the production of "The IPTS Report", a monthly journal targeted at European policy-makers and containing articles on science and technology developments, either not yet on the policy-makers' agenda, but likely to emerge there sooner or later.

For more information: http//:www.jrc.es Contacts: esto-secretary@jrc.es 

IPTS Technical Report Series, EUR 21301 EN

"SCIENCE IN TRADE DISPUTES RELATED TO POTENTIAL RISKS: COMPARATIVE CASE STUDIES"

Editors: Oliver Wolf, Dolores Ibarreta, Per Sørup (IPTS, Joint Research Centre, EC)

Authors: Erik Millstone and Patrick van Zwanenberg (Science and Technology Policy Research, University of Sussex, UK), Claire Marris (Institut National de Recherche Agronomique, STEPE (Societes, Techniques, Environnement, Politiques Economiques, Paris, France), Les Levidow (Centre for Technology Strategy, Open University, UK), and Helge Torgersen (Institute of Technology Assessment, Austrian Academy of Sciences, Austria)

Reviewers: Vern R. Walker (Hofstra University School of Law, US), Joel Tickner (Lowell Center for Sustainable Production, University of Massachusetts, US), Olivier Godard (CNRS, Laboratoire d'Econometrie de l'Ecole Polytechnique, France), Theofanis Christoforou (Legal Service, EC), C.J. (Kees) Van Leeuwen (IHCP, Joint Research Centre, EC)

Seville, Spain, August 2004

Published by:

EUROPEAN COMMISSION

Joint Research Centre

IPTS- Institute for Prospective Technological Studies

Edificio Expo, C/ Inca Garcilaso s/n

E-41092 Seville, Spain

http: \|www.jrc.es

(C) ECSC-EEC-EAEC, Brussels • Luxembourg, 2004 



\section{TABLE OF CONTENTS}

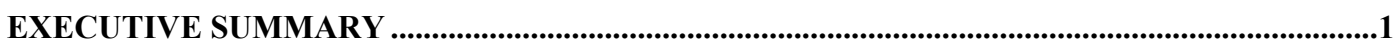

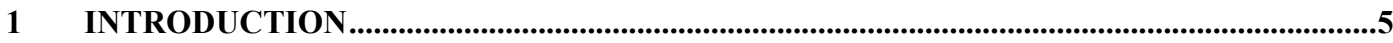

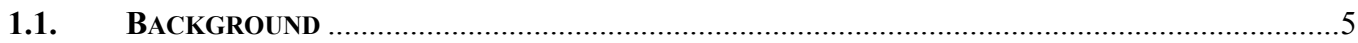

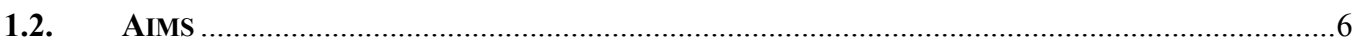

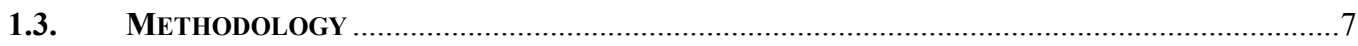

2 KEY ISSUES FROM THREE CASE STUDIES.....................................................................9

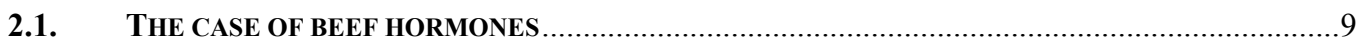

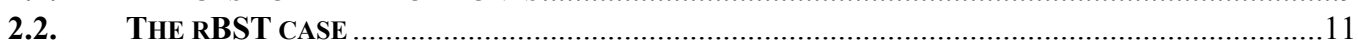

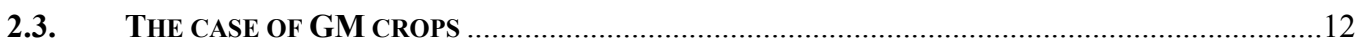

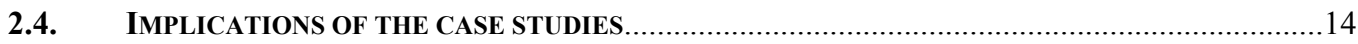

3 PUBLIC POLICY OFFICIALS: HOW THEY INTERPRET THE DISPUTES......................16

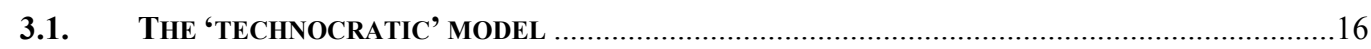

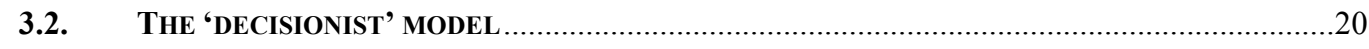

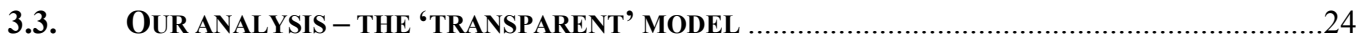

4 COMPETING FRAMING ASSUMPTIONS AND COMPETING ASSUMPTIONS ABOUT

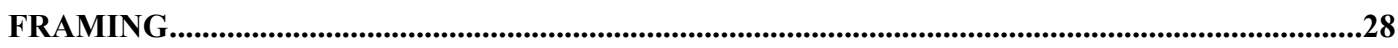

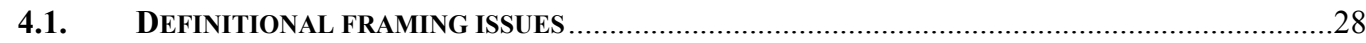

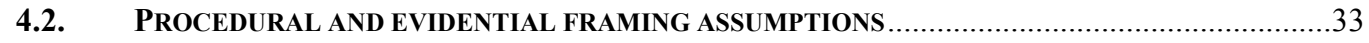

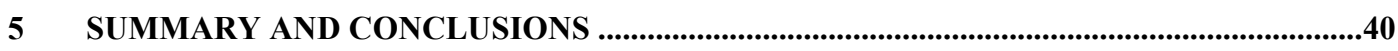

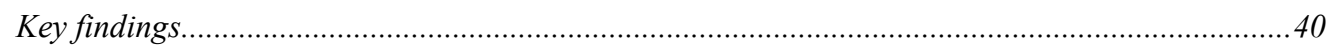

Appendix I: lists of interviewees ...............................................................................................................46

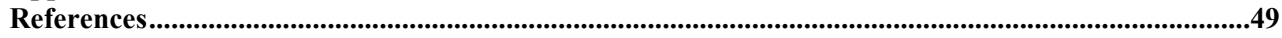

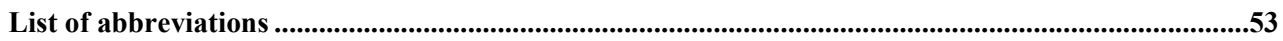





\section{Executive Summary}

This report on Science in trade disputes related to potential risks: Comparative case studies focuses on the role of science in policy-making, through the lens of a set of international disputes over the legitimacy of regulatory measures relating to food safety, public and environmental health.

The study deals with five jurisdictions namely Austria, France, the United Kingdom (UK), the United States of America (USA) and the European Community. The World Trade Organisation (WTO) though a non-jurisdictional institution was also included. Three case studies were examined across those jurisdictions, namely beef hormones, recombinant Bovine Somatotropin (rBST) and GM maize.

The report analyses some of the main science-related aspects of the occurrence and persistence of disputes and to indicate the conditions under which such persistent differences may be reduced.

Our key finding is that the core of the disagreements in those three disputes, between EU Member States and the European Commission on the one hand and the government of the USA on the other, concerns differences in a set of assumptions that we call up-stream framing assumptions. An important part of those framing assumptions concern what the Codex Alimentarius Commission calls 'risk assessment policy'. Risk assessment policy judgements have routinely played a key role in risk policy-making processes, but they have often remained implicit, unacknowledged and unexamined.

Risk assessment policy judgements are concerned with issues such as:

- which kinds of impacts are deemed to be within the scope of the assessment and which were outside it,

- which kinds of evidence to include and which to discount,

- how to interpret the available evidence,

- how to respond to uncertainties, and

- how much of different kinds of evidence would be necessary or sufficient to sustain different types of judgements.

The General Principles Committee of the Codex Alimentarius Commission says:

"Determination of risk assessment policy should be included as a specific component of risk management. Risk assessment policy should be established by risk managers in advance of risk assessment, in consultation with risk assessors and all other interested parties. The procedure aims at ensuring that the risk assessment process is systematic, complete, unbiased and transparent... Where necessary, risk managers should ask risk assessors to evaluate the potential changes in risk resulting from different risk management options." (Codex Alimentarius Commission, Committee on General Principles, Alinorm 03/41, July 2003, p. 126, paras. 13-16 emphases added)

Our findings suggest not just that 'risk assessment policy' issues should not be neglected, but that they have played, and continue to play, a pivotal role in causing inter-jurisdictional disputes. If important risk assessment policy issues were dealt with explicitly rather than 
implicitly, and if within individual jurisdictions risk managers were to take explicit responsibility for those policy issues, then policy-making processes might achieve greater democratic and scientific legitimacy than hitherto. In so far as a consensus could be reached between jurisdictions over risk assessment policy issues, inter-jurisdictional disputes would become less frequent and less intractable.

The importance, and contestability, of risk assessment policies is not widely acknowledged or appreciated, especially amongst public officials responsible for administering risk management regimes and their expert scientific advisors. When interviewed, they almost invariably described science-based policy-making in terms of one of two over-simplified models.

The first type of approach articulated by policy-officials can be encapsulated in what is termed a 'technocratic' model. A technocratic model assumes that risk policy should and can be decided solely by reference to scientific considerations and expert advice; on and only on the basis of 'sound science'.

The technocratic model does not, however, provide sufficient resources with which to understand the disputes over beef hormones, rBST and GM foods. The disputes are not simply a consequence of some jurisdictions accepting 'sound science' while in others the science is 'unsound'. In practice, we found that different scientific advisory committees provide competing representations of possible risks not because they are providing competing answers to an agreed set of questions, but because the questions that they are addressing and answering differ significantly. They may be equally sound, and nonetheless differ. There is more than one scientific answer to risk issues, because in different jurisdictions, different questions are being addressed.

The technocratic model is also incapable to explaining how policy can be made in conditions of acknowledged scientific uncertainty. Uncertain knowledge cannot uniquely indicate any particular policy conclusion. The prevalence of uncertainties is increasingly hard not to acknowledge, especially when different jurisdictions are in dispute, and their disputes revolve around competing scientific conclusions.

In response to the inadequacies of a technocratic narrative, an increasingly large portion of public policy-makers and their expert advisors now represent the processes in which they participate in terms of what is called a 'decisionist' model. This corresponds closely to what in the USA is known as the 'Red Book' model. Decisionism assumes that risk policy is, and should be, the product of a two-stage process, the first of which is purely scientific, often called 'risk assessment'. On this account, the scientific risk assessment is supplemented by social and political considerations, which also contribute to policy decisions in a process called 'risk management'. On this model, a risk assessment should not only be prior to, but entirely independent of, any and all risk management considerations and judgements. The 'decisionist' point of view is found very widely in all of the jurisdictions we examined, and represents the prevailing contemporary orthodoxy.

The decisionist model provides more resources with which to understand the occurrence and persistence of trade disputes than the technocratic model, since it can account for the fact that different jurisdictions may deem different levels of risk to be acceptable; but our 
research indicates that it is not sufficiently rich fully to comprehend the nature and complexities of these disputes.

The empirical evidence that we have gathered and analysed indicates that, both within the EU, and when comparing the EU with the USA and the WTO, disputes have occurred and persisted because:

- different judgements have been made about what the breadth and scope of scientific risk assessments should be

- different judgements have been made about the ways uncertainties should be handled by risk assessors, and the significance that should be ascribed to them,

- different judgements have been made about the benchmarks by reference to which the available evidence is interpreted, and

- different judgements have been made about the 'chosen level of protection' i.e. the extent to which those risks and uncertainties are socially acceptable.

These facts can effectively be represented in a third model of how science and governance interact. This third approach, which we call a 'transparent' model, assumes that sciencebased risk assessments play a key role in policy-making processes, but that they are routinely and inevitably influenced by the socio-economic and cultural contexts in which they are developed. This approach is consistent with the General Principles Committee of the Codex Alimentarius Commission's statement (cited above) outlining the defining characteristics of risk assessment policy.

The 'transparent' model assumes that non-scientific considerations play a distinctive upstream role setting the framing assumptions that shape the ways in which risk assessments are constructed and conducted. It implies that rather than leaving those assumptions implicit, and leaving risk assessors to take responsibility for non-scientific judgements, risk managers could provide their risk assessors with explicit up-stream framing guidance. Such framing guidance could, in turn, be legitimated through normal channels of democratic accountability. Our use of the term 'transparent' is not intended to suggest that current practices transparently fit this model, but rather to suggest that if they were transparent, they would be seen as operating in accordance with this model.

This transparent model provides the resources with which to explain why regulatory disputes occur and why they persist, but it also serves a normative function by suggesting some of the conditions under which such disputes may be resolved.

The transparent model does not imply that disputes are inevitable or that they are irresolvable. It implies rather that they are more likely to be resolved if the existence and importance of risk assessment policy considerations were acknowledged and if they were consistently deployed in a transparent fashion.

It also implies that disputes might be avoided if, in advance of requesting their expert advisory committees to provide science-based risk assessments, risk managers in different jurisdictions would collectively explore the extent to which a consensus may be reached about the assumptions that should frame those risk assessments. If such high level negotiated agreements were reached, the frequency and severity of science-based regulatory trade disputes might well be markedly diminished. 
If on the other hand such prior agreements are not reached, and if, for reasons that may be scientifically and democratically legitimate, different jurisdictions adopt risk assessment policies that reflect national, social and cultural diversities, then risk management regimes may continue to differ, if only at the margin. Those differences may, however, be lawful under both national, international law, and sustainable over the long-term, but the potential benefits of regulatory harmonisation and the elimination of non-tariff barriers to trade would be forgone.

If the role played by upstream assumptions was explicitly acknowledged, then this might also discourage adversarial invocations of 'sound science', both domestically and against other jurisdictions. This in turn could help to deter formal trade disputes, and perhaps might also lead individual jurisdictions to reflect on their own framing assumptions, thus increasing public accountability and enhancing democratic legitimacy. 


\section{Introduction}

\subsection{Background}

Policy-makers are understandably keen on reconciling differences between the regulatory standards adopted by different jurisdictions (some even talk of convergence) and they often look to science, embodied in expert advisory committees, to provide the facts to which policies can be anchored. Procedural mechanisms have been developed within the European Union (EU) and under the auspices of the World Trade Organisation (WTO) to try to reconcile those differences using science, but they have not always been successful.

Several regulatory and trade disputes have taken place, the potential for new ones to arise remains undiminished, and a few disputes have exhibited remarkable longevity and persistence. Although the number of disputes has been rather small, their impact has been disproportionately large.

There has been a growing recognition that science, on its own, cannot settle policy questions, and consequently that policy-makers need to take both scientific considerations and other legitimate (non-scientific) factors (sometimes referred to as 'OLFs') into account. A key difficulty has been to understand how, within the policymaking process, scientific considerations and other relevant factors can be separated from each other and yet ultimately joined together.

One response has been to invoke the concept of 'precaution' because it has frequently been seen as providing the means with which policy-makers can respond to persistent scientific uncertainties and yet reach legitimate decisions. This study aimed, amongst other things, to explore how the concept of 'precaution' is being interpreted and invoked in the context of regulatory decision-making.

The project studied three disputes namely those over the acceptability of risks from beef hormones, recombinant Bovine Somatotropin (rBST) and Genetically Modified (GM) maize. The perceptions of, and policies towards, those disputes were studied in Austria, France the United Kingdom (UK), the United States of America (USA), the European Commission and the WTO. This report focuses on several empirical and analytical questions about science, governance, precaution and trade policy.

A crisis of science and governance is perceived in differing ways both within and between various national and international policy-making jurisdictions. ${ }^{1}$ There are differences amongst EU Member States but there are also differences between the EU and the USA. Amongst the most important differences are those concerning what are now being termed as 'risk assessment policies'. The phrase 'risk assessment policies' is being used to refer, for example, to decisions about how scientific advice should be obtained and used, the scope of the agenda that risk assessors are expected to address, the implications for policy-making in the context of scientific uncertainty, the conditions under which precaution can be applied. This concept seems to be important, even though it has only been articulated in the very recent past, and its full significance has yet to be widely appreciated. 
In 2001 a working party of the Codex Alimentarius Commission (a joint body of the UN Food and Agriculture Organisation and the World Health Organisation which, under the provisions of rules of the WTO, sets baseline standards for traded food products) defined 'risk assessment policy' in the following terms:

The concept was first introduced in 2001, but the most recent account was provided by the General Principles Committee of the Codex Alimentarius Commission in 2003. It said:

"Determination of risk assessment policy should be included as a specific component of risk management. Risk assessment policy should be established by risk managers in advance of risk assessment, in consultation with risk assessors and all other interested parties. The procedure aims at ensuring that the risk assessment process is systematic, complete, unbiased and transparent...Where necessary, risk managers should ask risk assessors to evaluate the potential changes in risk resulting from different risk management options." (Codex Alimentarius Commission, Committee on General Principles, Alinorm 03/41, July 2003, p. 126, paras. 13-16 emphases added)

The wording of the Codex definition implies that risk assessment policies may be either explicit or implicit, although suggesting that it is preferable for risk assessment polices to be explicit rather than implicit, and set out by risk managers in advance of expert deliberations on risk assessment.

This study sought to explore if there are conflicting implicit risk assessment policies amongst the jurisdictions, and how far those differences could help explain unresolved scientific and policy disagreements. Those differences may be important because EU Member States have taken collective decisions to try to achieve convergence amongst their regulatory measures. Similarly, the GATT Treaty was developed, and the WTO created, in part to diminish differences in regulatory policies because they were perceived to constitute non-tariff trade barriers. The treaties of both the EU and the WTO are worded in ways that some have interpreted as suggesting that science, scientists and expert advisory committees can often provide the necessary, and perhaps even sufficient, means through which regulatory differences will be reconciled. Increasingly, however, those treaties are being interpreted and applied in ways that contradict those expectations.

\subsection{Aims}

This study aimed to explore the ways in which science has been used and invoked to explain or resolve regulatory differences. It also aimed to discover how standards can legitimately be set in the face of scientific uncertainties and contested interpretations.

This report aims to provide an analysis of some of those key differences to clarify what it is that is being disputed and why science hasn't been able to reconcile policy differences, and the conditions under which the frequency and severity of such disputes might be diminished. Are the disputes purely scientific ones, and if not what kinds are they?

This report also has a broader aim because it aspires to provide an account of how science-based policy-making can be both scientifically and democratically legitimate, 
and to outline the implications of that account for the future of inter-jurisdictional disputes over regulatory standards.

\subsection{Methodology}

The empirical work for this project was initially organised by gathering and analysing documentary materials on the disputes concerning beef hormones, rBST and Bt-maize, both in textual and electronic forms. Material was gathered on both the procedural and substantive aspects of risk appraisal and decision-making from each of the jurisdictions. Preliminary reviews of the case studies were then drafted, and they served as a basis for a discussion through which an interview strategy was developed. That strategy was developed at a team meeting, and interviews were subsequently conducted, and their results analysed to generate the findings outlined in this report.

For this project a wide range of, what in this context we call, 'key protagonists' were interviewed. A list of the institutional affiliations of those protagonists is provided in Appendix I. The phrase 'key protagonists' is here used to refer firstly to public officials with responsibility for administering risk policy-making regimes and secondly to scientists who make, or who have made, direct inputs into the policy-making process as members of official expert scientific advisory committees. Beyond those two groups, we also interviewed a wider range of stakeholders including other scientists with relevant expertise but who are not members of officials expert advisory committees, as well as with representatives of corporate interests on the one hand and consumer welfare and environmental groups on the other. The main purpose of the stakeholder interviews was to provide indications about how the policy-making process was understood from the perspective of different stakeholders and to enable comparisons to be made between official accounts and those of various stakeholders. We selected and interviewed individuals by reference to their institutional locations, but we were unable directly to establish how representative of those groups they might be. The findings of those interviews were then digested, analysed and reported in the form of national reports. Once those documents had been circulated, a second project meeting was held. That meeting focussed on identifying and clarifying the issues to be discussed in this overall report.

In gathering and analysing our evidence we sought to address a set of empirical questions and a set of analytical questions. The empirical questions were:

- Why have disputes occurred over the safety of beef hormones, rBST, and GM maize?

- How have the protagonists and the broader policy community interpreted those disputes?

- What assumptions do the protagonists make about the contribution of science to regulatory decision-making?

- What do the protagonists deem to be legitimate ways of obtaining and using scientific advice in policy-making?

- What do the protagonists consider to be a legitimate, and a non-legitimate, exercise of precaution? 
- What do the case studies indicate would be a legitimate, and a non-legitimate, exercise of precaution?

and the analytical questions were:

- What lessons can be drawn from the disputes over the safety and acceptability of beef hormones, rBST, and GM maize?

- What are the consequences of adopting different ways of coupling science into policy-making?

- Which models of science in policy are implicit in, and/or consistent with the ways in which these disputes have been treated by the different jurisdictions?

- What are the implications for reconciling regulatory differences in risk policymaking processes?

The categories under which information was gathered from interviews is given in Appendix II. 


\section{Key issues from three case studies}

\subsection{The case of beef hormones}

The beef hormones case is pivotal because the provisions of the Sanitary and Phytosanitary (or SPS) Agreement were drawn up in the light of the beef hormones dispute, and were designed to deal with disputes of that type.

The European Union moratorium on the introduction of those hormones, and on the import of US hormone-treated beef, was complicated by the fact that their use was not just deemed to be acceptably safe by the US Federal Authorities namely the US FDA and the USDA, but also because their use was deemed acceptably safe by the Joint FAO/WHO Expert Committee on Food Additives (JECFA). The Lamming Committee, which advised the European Community, also produced a report in 1982 indicating that the banned hormones were 'acceptably safe', as did the EC Scientific Committee for Animal Nutrition in November 1982, the EC Scientific Committee for Food in February 1984, and a 1995 EC Scientific Conference on Growth Promotion in Meat Production concluded that the hormones were acceptably safe. In each of those cases, judgements of acceptability of risks were made even though they were ostensibly purely scientific reviews.

The World Trade Organisation's Dispute Panel and its Appellate Body ruled against the European Community, and that ruling was interpreted by some as implying that non-EC countries could compel the EC/EU to accept their food and agricultural products, even if the European Commission was not convinced that those products were acceptably safe. The judgement of the Appellate Body was however rather more subtle and nuanced. It did not rule that the EU had no scientific evidence of risk, nor that beef hormones are unproblematically safe, but concluded rather that the EC had not followed the rules concerning the requirements for, and conduct of, an appropriate science-based risk assessment. In practice, the EC did have had some evidential grounds for its concerns about the safety of those hormones, but those data did not derive from studies of the consequences of consuming beef that contained residues of growth hormones. The data came rather from studies of the direct medical use of some of the hormones in pharmaceutical products and treatments. The WTO Appellate Body ruled, in effect, that those data were not directly relevant to the alleged risk that the European measure was designed to control. Specifically, the Appellate Body concluded that the EC had not provided a sufficient case: “...on the risk to human health from residues in meat from animals treated with one of the six hormones for growth promotion purposes in accordance with good agricultural practice..." The adjudication implied, moreover, that what the EC had provided was not sufficient to be deemed an adequate risk assessment capable of providing a basis for the specific measure that had been imposed.

The practice of individual EU Member States has also been noteworthy. In several European countries, the official position has long been that the use of beef hormones was not acceptable, but little evidence emerged indicating that any formal risk assessments were conducted. Indeed, the countries that have been least enthusiastic about accepting beef hormones have been amongst those that devoted least efforts to formal scientific risk assessments of these compounds, at least prior to the imposition of the trade-restrictive measures. The converse also applied because it was in the UK, 
where official policy has been in favour of accepting beef hormones (and rBST too), that some kinds of formal risk assessment had taken place. That contrast is slightly oversimplified, however, because some European Member States have claimed to have conducted a risk assessment, even though representatives of other States argue that those discussions fall short of what they would count as a proper risk assessment. The question of what counts as an adequate 'risk assessment' is, obviously, crucial.

The judgements of the WTO Dispute Panel and the Appellate Body implied that risk management measures can violate the SPS agreement if they are not 'based on' a relevant risk assessment. More specifically there needs to be a 'rational relationship' between the measures and the risk assessment on which they purport to be based. The WTO adjudicators made it clear, however, that they interpreted the requirement for a 'rational relationship' in a broad rather than a narrow way because they did not assume that only one risk management policy decision could stand in a 'rational relationship' to a given risk assessment. On the contrary, they recognised that a fairly broad range of different decisions could be based on any given risk assessment, and that risk assessment was itself not a univocal activity. They insisted however that the risk management judgement should be based on a scientific risk assessment rather than being made without any reference to any such assessment.

According to the SPS agreement, legitimate measures should also not discriminate as between home-produced and imported products, or use measures that are more traderestrictive than necessary to attain a level of risk deemed officially acceptable. On the other hand, the judgements of the WTO adjudicators also implied that a WTO member can apply any standard of acceptable risk from the highest to the lowest, even a zero risk, just as long as that benchmark is applied consistently and in a non-discriminatory manner.

The adjudications in this dispute also imply that a WTO member can adopt a risk assessment that is significantly at variance from that accepted by global expert advisory committees that operate under the auspices of Codex. The beef hormones case also indicates that scientific uncertainties can be used as grounds for a temporary, but not for a permanent, ban; on the other hand, it also implies that temporary measures could be extended for quite long periods of time.

A more detailed scrutiny of the scientific considerations and assessments to which both the USA and the European Community have appealed in support of their positions reveals that the precise questions that the European risk assessors are addressing are significantly different from those that have been addressed in the USA. The US approach has been predicated on the assumption that, since the hormones at issue are chemically quite similar to the animals' naturally occurring hormones, and since hormone residues in meat from cattle produced using hormones additives are similar to those found in traditionally produced meat, their use poses no significant hazard. The USA also argued that the residues of hormones in meat are not only chemically quite similar to those found in other natural foodstuffs, but also that humans ingest higher quantities of hormones by eating other natural foods than in meat from animals treated with hormones. The USA also argued that humans endogenously produce relatively high levels of the same chemically active compounds, and the USA claimed that additional intakes from residues in meat is very small compared to the overall intake. 
Subsequently, moreover, they have argued that the use of growth-promoting hormones in the USA grew noticeably after the early 1970s, but no adverse trends can be discerned from the US domestic public health epidemiological data.

In contrast, in 1999 the European Commission's Scientific Committee on Veterinary Aspects of Public Health argued that the incidence of breast and prostate cancers in the US population are about $20 \%$ higher than in the EU, and that those tumours are predominantly hormone-dependent lesions. ${ }^{2}$ The approach in the EU has not presumed the safety of the compounds. Since at least the mid-1990s, the European authorities have been indicating that, before they can be satisfied that the use of this material is acceptably safe, they would require a wider range of different kinds of studies, and under most headings significantly more studies. Consequently a European risk assessment would need to be more comprehensive than was previously required by the USA.

Since the late-1990s European risk assessments have been refined to consider the possible adverse effects on not just average consumers but especially on vulnerable groups, and in particular to pregnant women and pre-pubescent children; while in the USA the assessments of risk have not focussed on those specific groups. There appears, however, to be nothing in WTO statutes or case law that prevents a jurisdiction from refining the scope of its consideration of risks in that kind of way.

\subsection{The rBST case}

The recombinant Bovine Somatotropin (rBST) case is interesting in part because of a contrast it provides to the previous case. rBST is being lawfully used in the USA, but its use in dairy cattle remains unlawful in the EU, although the import of milk or dairy products from cows treated with rBST has not been banned. The USA has not initiated a WTO dispute with the EC over rBST and one is not anticipated. One widely held, but not universally accepted, view is that the European Commission learnt several lessons from the beef hormones case which have subsequently been applied to the case of rBST. The way in which the EC has dealt with rBST has been noticeably different since the mid-1990s compared to the preceding period. In March 1999 two separate official risk assessments of rBST were delivered to the Commission, one focussed on the possible human health hazard to consumers of milk produced by cows treated with rBST and the other on the potential risks to the health and welfare of dairy cows receiving rBST treatment. $^{3}$ Prior to that time, the Joint Expert Committee on Food Additives (JECFA) of the WHO and UN FAO had assessed rBST and deemed its use to be acceptably safe for human consumers of milk and dairy products. The only other formal European risk assessment of the possible effects on human consumers of ingesting milk from rBSTtreated cattle had occurred in the UK, but the history of that process was complex and contested. ${ }^{4}$ While many European countries strongly supported the Commission's policy of a moratorium on the introduction of rBST there is little evidence that their support was directly based on domestically-conducted risk assessments, at least of a type that might be deemed adequate in the event of a formal dispute.

The European Commission had asked the Scientific Committee on Veterinary Measures relating to Public Health (SCVMPH) to "...assess the possible direct and indirect adverse effects on public health caused by the use of BST under normal conditions." 
(emphasis added) The inclusion of the word 'indirect' and the phrase 'under normal conditions' extended the scope of the assessment beyond that which might otherwise have been required. In a parallel exercise, the Scientific Committee on Animal Health and Animal Welfare (SCAHAW) was "... asked to report on the incidence of mastitis and other disorders in dairy cows and on other aspects of the welfare of dairy cows." (emphasis similarly added)

When, however, the US FDA and JECFA had previously assessed the risks of rBST they had, effectively, confined their focus to possible adverse effects on human consumers. They both acknowledged that there was evidence that the administration of rBST had a noticeable effect on mastitis in dairy cows, but discounted that evidence as having no direct bearing on the health of human consumers, to which their terms of reference supposedly confined them. US officials have, moreover, indicated that in the USA the increased risk of mastitis in cows treated with rBST is acknowledged to occur but it is not deemed to be a problem of veterinary health but rather a problem of 'animal welfare' that may be mitigated by 'herd management'. That shift in linguistic idioms was used in the USA retrospectively to reclassify the phenomenon as a non-health issue.

The SCVM Public Health risk assessment was inconclusive; the committee identified prima facie evidence of a possible hazard, but could not reliably estimate the probability or severity of adverse outcomes. If that had been the full extent of the evidence of risk it would almost certainly not have been sufficient to sustain a measure permanently to ban rBST from the EU. It might, however, have provided a scientific basis for a temporary measure, pending the receipt of the results from further studies that could diminish the key uncertainties.

In the event, however, the Scientific Committee on Animal Health concluded that "BST administration causes substantially and very significantly poorer welfare because of increased foot disorders, mastitis, reproductive disorders and other production related diseases. These are problems which would not occur if BST were not used and often results in unnecessary pain, suffering and distress." That scientific conclusion was interpreted by European policy-makers as providing an adequate and rational basis for a measure that bans the use of rBST in the EU indefinitely. That judgement has not been the subject of a WTO Dispute. There is no indication that such a dispute would be initiated on the part of the USA or, if it did, that the plaintiff would prevail. The example nonetheless helps to illuminate science-policy issues that arise in trade disputes.

That example provides direct evidence that different jurisdictions do, and legitimately can, frame and conclude their risk assessments in different ways, and that a jurisdiction can adopt measures that are more restrictive than those indicated by Codex and yet not be vulnerable to a WTO dispute, as long as a scientific risk assessment has been conducted, and as long as it provides a basis for the consequent measures adopted.

\subsection{The case of GM crops}

The evolving debate about GM crops highlights a range of factors that did not emerge from the beef hormones or the rBST case. It was evident even in the early 1990s that 
Europeans defined the scope of their risk assessment of the environmental release of GM crops differently from the framing adopted in the USA.

In this report the relevant product is Bt maize. GM Bt maize is produced by inserting a gene that originally came from a microbe known as Bacillus thuringiensis, long used as a foliar spray against insect pests. When the gene was inserted into maize, a prime target was the European corn borer, a serious pest in the USA as well as Europe. The risks have been regulated in the EU by national authorities under the Deliberate Release Directive, and in the USA by the EPA under pesticide legislation.

The EPA claimed that Bt crops would greatly reduce insecticide sprays, thus bringing environmental benefits. In the mid-1990s, when it began to approve Bt 'plant pesticides' in GM crops, environmental NGOs protested that their extensive use could lead to insect resistance, thus undermining not only the Bt crop but also the efficacy of microbial Bt sprays, as an alternative method for organic agriculture. Eventually the EPA undertook to regulate this risk, thus preserving Bt as a 'public good'.

Under the provisions of European Directive 90/220, risk assessments of the environmental release of GM crops were, even in the early and mid-1990s, framed more widely than those then deemed adequate by the US authorities. European risk assessors were supposed to take into account possible adverse effects on flora and fauna whatever their agricultural or commercial significance; although some commentators have argued that they did not always do so. Under the provisions of the revised Directive 2001/18, however, the scope of scientific assessments of the environmental release of GM crops has been extended explicitly to include long-term and indirect effects as well as shortterm and direct effects on flora and fauna.

In both the EU and the USA, however, there continue to be energetic debates about the development and application of genetic technology to food and agricultural crops, and in all jurisdictions those debates have both scientific dimensions and non-scientific factors too. One consequence of the dynamics of those debates has been that, more often implicitly than explicitly, an increasingly wide range of different kinds of risk considerations are being taken into account in all European jurisdictions, and in the USA too, and different bodies of scientific evidence are being considered necessary and/or acceptable. For example, molecular biology is no longer considered sufficient on its own: population genetics, entomology, toxicology and farm management regimes are increasingly taken into account in risk assessments of GM crops.

In the USA, a report from the National Research Council outlined a range of risk considerations that the US authorities had not focussed on, which suggests that in the near future pressure will grow for the US authorities to broaden the scope of their risk analyses. ${ }^{5}$ There are no European jurisdictions in which the scoping of risk assessments has reached a stable equilibrium; all are in a state of flux, and all are, explicitly or implicitly, under review.

In the USA official risk assessments of crops that have been genetically engineered to produce an insecticidal toxin, known as Bacillus thuringiensis (or Bt), have devoted most of their attention to the risk that the insect species being targeted might develop resistance to the Bt-toxins that the plants are designed to express. Were that to occur, it 
would diminish the efficacy of those Bt plants, and also reduce the effectiveness of Bt foliar spays, which offer a potential alternative to agrochemicals.

One European commentator remarked, of the USA: "In the case of GM crops, in the USA, even amongst the NGOs, the discourse is predominantly concerned with the maintenance of refuges to manage the problem of insects developing resistance to Bt. The discussion is framed in terms of managing changes...But the evidence and debates about the possible effects on the Monarch butterfly revealed gaping holes in the US risk assessments."

One question considered by US risk assessors has been whether there are other technologies that could provide a second line of defence. In the EU, on the other hand, that issue has been approached somewhat differently. Expert advisory groups have sometimes argued that pest resistance does not constitute a problem because farmers could always revert to using chemical rather than botanical pesticides.

Another risk, harm to non-target insects, was in any case regulated (in both the USA and EU) but became a prominent issue only in the late 1990s, after new experimental results cast doubt upon earlier safety assumptions. There ensued arguments over the criteria and quality of evidence to demonstrate whether or not such harm would occur in commercial fields. Since the late 1990s, when evidence emerged of possible risks to non-target species such as lacewings and the monarch butterfly, both US and European risk assessments have increasingly needed to deal with the possibility of adverse unintended effects to non-target species. ${ }^{6}$ On both sides of the Atlantic, such evidence has stimulated both debate and research.

\subsection{Implications of the case studies}

A growing body of evidence has emerged showing that one of the key reasons why risks (such as those from GM crops or synthetic hormones) are assessed differently within different jurisdictions is because different assumptions are being made about which categories of risk need to be taken into account. As long as that diversity persists, but is not acknowledged for what it is, nor addressed explicitly, the potential for trade disputes could continue between EU and USA, and within the EU.

Currently, officials in all jurisdictions tend to argue that differences in regulatory measures occur either because one side (usually the other) is 'not based on sound science' and/or because the contrary policy is based on social and political factors rather than scientific ones. A key debate focuses on whether or not 'other non-scientific factors' have any legitimate role to play in policy-making. Those adopting what we term a 'technocratic' representation of science and policy (see Figure I on page 18) argue that they have no legitimate role to play - measures should be based on science alone, whereas those adopting what we term a 'decisionist' model (see Figure II on page 22) believe that other factors can, under some conditions, be legitimately considered. Neither of those interpretations, however, provide the resources with which to understand that regulatory measures often differ because the risk assessments on which they were based had been framed by different upstream assumptions about the scope of scientific deliberations and the kinds of evidence to be included or discounted. 
One way in which trade conflicts could be diminished therefore would be by acknowledging, and making explicit, those upstream framings. It could then be easier to see why the disparity between different risk assessments had arisen. Some jurisdictions might extend the scope of their deliberations to include aspects that they had not taken into account, while conceivably others might choose to circumscribe their agenda more narrowly. Currently, both the EU and the USA are considering putative adverse effects from GM crops on both target pest species and non-target species, but they differ for example in the extent to which they deem the presence of modest amounts of GM material in organic produce to be problematic.

Our analyses of the diversity of risk assessments, and of debates about risk management policies, indicate that inter-jurisdictional disputes within the EU and between the EU and the USA, are not so much about divergent interpretations of the same data, but are concerned with risk assessment policy questions such as: how many, and which, different lines of scientific inquiry should be pursued, which effects to deem as 'harmful', which kinds of evidence are necessary and/or sufficient before, for example, farm-scale trials or commercial cultivation could be deemed acceptably safe?

Our analysis of the history of these three case studies therefore supports the conclusion that the reason why these disputes occur and persist is not just because different groups of scientists provide different answers to an agreed set of questions based on the same set of data, but because in different jurisdictions slightly different scientific questions are being asked, focussing on various aspects of the overall set of risks. If a prior agreement could be reached, amongst policy-makers as well as amongst scientists and other stakeholders about how risk assessment should be framed, and which sets of concerns need to be addressed and which excluded, an important source of conflict and disputes would be resolved.

If the role played by upstream assumptions was explicitly acknowledged, then this might also discourage adversarial invocations of 'sound science', both domestically and against other jurisdictions. This in turn could help to deter formal trade disputes, and perhaps might also lead individual jurisdictions to reflect on their own framing assumptions, thus increasing public accountability and enhancing democratic legitimacy. 


\section{Public policy officials: how they interpret the disputes}

We conducted interviews with public officials and representatives of the broader policy communities to try to map the ways in which they think and talk about the (actual and ideal) role of science, and other legitimate factors, in risk appraisal and decisionmaking, both without their own jurisdictions and those of others. The aim was to map the range of different understandings of the nature and role of risk assessment, evidence, uncertainties and precaution. The range of different perspectives adopted by representatives of the various national and multi-national jurisdictions could, to a useful first approximation be characterised in terms of two competing general models of science and policy-making, and the logic of risk appraisal and decision-making. These models highlight many, but not all, key features of the assumptions and statements of key protagonists. The analysis of those differing understandings may, however, serve at least two purposes; they may serve both descriptive and prescriptive purposes.

We term these two models I) the technocratic model and II) the decisionist model. That terminology has its roots in the broader science policy literature. ${ }^{7} \mathrm{We}$ will introduce those models and then indicate how they represent the views of key officials and other protagonists and indicate how they were exemplified in the comments of the key protagonists. In the light of the foregoing discussion we will then explain why our analysis of the case studies suggest that those models are inadequate, and will introduce an alternative model that provides a more adequate diagnosis of the source of disputes and indications as to how the frequency and severity of those disputes might be diminished.

\subsection{The 'technocratic' model}

One classical account of science-based policy-making can be represented by what we term 'the technocratic model'. It assumes that policy decisions about technological risks can and should be based on, and solely on, scientific considerations. Historically, regulatory policy-making for the protection of consumers and public health was often officially represented as if it were based on, and only on, 'sound science'. The key characteristics of this classical 'technocratic' model are that it assumed, in effect, that science operates in complete independence of social, political, cultural and economic conditions, and that science provides not just a necessary, but a sufficient, basis for policy decision-making. The technocratic model can be represented graphically and is shown in Figure I.

Figure I - The technocratic model

Policy is based on sound science

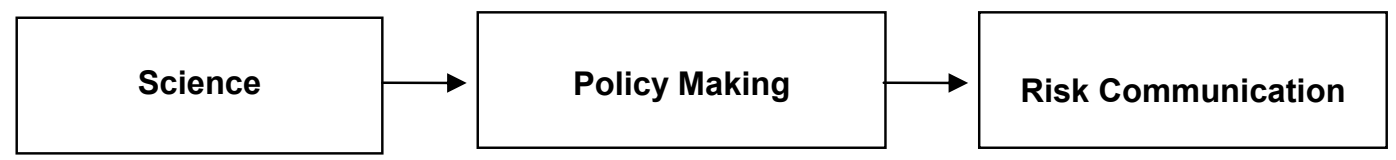


The graphic representation of the technocratic model portrays a linear process based solely on scientific considerations. It implies that policy decisions can and should derive only from scientific judgements, and that risk communication is a unidirectional process running from the experts to the government and hence to industrial stakeholders and the general public.

This model can and has been used by public officials on both sides of the Atlantic, for a variety of descriptive, normative and rhetorical purposes. In our research it was not uncommon for interviewees to argue that policy should be based on, and only on, sound science, even though in practice some jurisdictions have not always conformed to that ideal; although most commonly officials argued that the policy regime for which they were responsible did conform to the ideal type. Some argued that disputes between jurisdictions arose because other regimes made judgements by reference to nonscientific considerations, including political ones while their policies were based solely on sound science. For example, a representative of the US biotechnology industry trade association challenged the entire legitimacy of our study by arguing that "The issue is the adequacy of the risk-assessment process...which should exclude politics. Your study presumes that US-EU differences derive from different scientific opinions, but the disputes are based on politics. It would be interesting to investigate the EU Member States in your study, because they have the problem (of political interference), but why study the USA too? ...In the USA, science rules regulation."

In a similar vein, a member of a UK expert scientific advisory committee argued that "...the USA and UK and some of EU took a purely scientific take on beef hormones, but economic political and consumer considerations intruded into the EU's positions." When, however, that individual was asked if US policy is pure science, free of all politics and economics he responded "you must be joking", implying that policies on both sides of the Atlantic have been hybrids of science and politics.

Several French and European Commission officials interpreted existing disputes about scientific judgements as consequences of the misuse of science, which in those cases had been manipulated by interest groups. One interviewee argued that, in the early 1990s, European Community food safety regulations were based on political compromises rather than on science - and that is why they are now being challenged by other jurisdictions. That official drew a sharp distinction between the harmonisation of previously existing national norms and the establishment, as in the case of GMOs in the late 1990 s, of an entirely new set of rules for a new type of product, implying that while the former may not have been purely scientific, the latter now was.

It was noticeable, however, that those who accused other jurisdictions of mis-using science could not explain how, in those jurisdictions, the science was being used - other than by pointing to divergences from their preferred representation of the science. They typically interpreted the existence of disagreements as sufficient evidence that the 'other' scientists were less than fully scientific. For example, several officials interpreted Austria's assessment of the risks of GM crops as 'un-scientific' and as 'motivated by politics', but none of them could identify any of the arguments used by Austria, and few appear to have studied the documents produced by the Austrian government in support of its ban on GM maize. They consistently referred to the response of the European Commission's Scientific Committee on Plants (SCP) which 
had rejected the Austrian arguments - but were unfamiliar with the SCP's specific arguments. From an Austrian perspective, it was noticeable that Codex risk assessments were viewed as "...political decisions wrapped up in science".

More generally, there are members of expert advisory committees in several of the jurisdictions that insist that what they do is sound science, and any other groups reaching contrary conclusions must de facto be unscientific. Whilst biased or shoddy scientific work is always a possibility, that insistence was problematic precisely because all jurisdictions were criticised by representatives of some other administrations as being un-scientific. A significant minority of officials (especially in France, and the USA, but less so in the UK, Austria and the European Commission) argued that, for example: “.... in the absence of political controversy, 'calm' science can and does resolve trade conflict." Similarly others argued that "What is needed to resolve trade conflicts is simply more science, more scientific data - not a different kind of science."

In other words, technocratic models of risk appraisal and decision-making are being articulated in some parts of all the jurisdictions, and technocratic diagnoses of the occurrence and persistence of disputes are also quite prevalent.

The concept of precaution can be difficult to comprehend from a technocratic perspective. Precaution is most commonly understood as a consideration that arises if, but only if, the underlying science is uncertain. If one assumes that the scientific basis for decision-making is sound and sufficient, then precaution appears otiose and irrelevant. From a technocratic perspective, policy-making is typically either represented as being precautionary because it is based on sound science; or alternatively, because policy decisions are based on sound science, unscientific considerations such as 'precaution' are irrelevant.

The US government, which has expressed concern about European interpretations of precaution and frequently argues that its own policy judgements are based primarily on sound science, responded to the European Commission's Communication on Precaution by articulating an account of precaution as the approach that the US government had been taking since the late nineteenth century. For example, the US FDA has asserted in 2000 that: "U.S. regulators have been world leaders in exercising precaution in regulatory systems for food and environmental safety since before the turn of the last century."8 According to the FDA's account, acceptance of 'a precautionary approach' can and should be equated with the establishment and operation of an anticipatory regulatory regime that requires scientific risk assessments before authorisations of novel ingredients. On this view, a non-precautionary approach would be one that did not require any official assessment of the risks or pre-authorisation. The FDA argued that the mere existence of a positive list system, under which anything that is not explicitly permitted is banned, constitutes a full and proper exercise of precaution.

At the technocratic end of the spectrum, the most stark view expressed by an official at the European Commission was similar to the American perspective, namely that: “...precaution...is just a masquerade for protectionism which allows decisions to be made in an arbitrary fashion and without any regard for 'sound-science'. The Commission's Communication on the Precautionary Principle has justified the fears of its [American] critics. It is used simply as a fig leaf to justify bans." 
An official at the US EPA took a rather different view of precaution arguing that: "For the sake of accommodating public perception, we require companies to spend funds to do research which is not necessary in scientific terms. We have a higher standard of risk assessment...[that is strictly necessary on scientific grounds.] Our approach...is more precautionary - indeed, the ultimate in precaution - because there is no scientific basis for some of our data requests."

A technocratic model seems to be particularly attractive to multi-lateral jurisdictions. Because they aim rapidly to achieve regulatory convergence, the prospect of an objective, neutral and uncontroversial basis for standard setting, or failing that one that is reductionist and majoritarian, is understandably attractive.

When policy-makers adopt a technocratic model, they can represent their policy decisions as deriving solely from the advice of scientific experts. Our analysis of the three case studies indicates that technocratic rhetoric and idioms have sometimes provided policy-makers with an apparent scientific legitimation for what were really contestable policy judgements.

One important difficulty with a technocratic model, however, is that it can also be a recipe for paralysis in the face of conspicuous scientific uncertainty. If the science is uncertain and inconclusive, science cannot decide policy. That may explain why, in the USA, where independent experts have repeatedly questioned the safety of products such as rBST, the FDA denied that any significant uncertainties remain to be addressed. ${ }^{9}$ Technocratic regimes consequently have a powerful incentive to try to conceal or understate policy-relevant scientific uncertainties, because the indecisiveness of science undermines the legitimacy of both the decisions and the decision-making institutions. Once disputes amongst different groups of experts arise, however, the resulting disputes become difficult to understand or resolve.

Although an influential minority of public officials have adopted or articulated technocratic assumptions and idioms, their assumptions are increasingly widely being seen as problematic. Because the scientific basis of policy-making is chronically uncertain, it is very difficult to defend the claim that policy can be decided solely by reference to 'sound science'. In the exchange between the European Commission and the US authorities over the interpretation of precaution, both sides accept that "...complete scientific certainty is the exception, rather than the norm..."10

In recent years, moreover, a growing proportion of policy-makers have come to assume that policy decisions are not just about the science of risk but also about the social acceptability of risks in exchange for anticipated benefits, and other social, economic and ethical considerations too. ${ }^{11}$ Some have, however, tried to argue that judgements of the acceptability of risks are essentially scientific judgements that members of expert advisory committees can and should take. ${ }^{12}$ That approach is however not widely accepted. 


\subsection{The 'decisionist' model}

The technocratic model has been frequently criticised as providing an over-simplified and unrealistic representation of the policy-making process. Since the early 1970s a growing proportion of academic policy analysts, and many public officials, have acknowledged that because of the uncertainties in the underlying science, scientific considerations can never by themselves determine policy-decisions. ${ }^{13}$

Commentators have also argued that, even though it may be possible to diminish, and even perhaps sometimes to eradicate the scientific uncertainties, scientific considerations can never, by themselves, determine policy outcomes. On this view, risk policy involves making judgements about the acceptability of risks, and of the uncertainties too, in exchange for some presumed or anticipated benefits. Judgements of that kind, which are concerned essentially with trade-offs, are understood to be value judgements which no amount of scientific information, theories and data could decide. Official commentaries on risk policy issues have consequently increasingly abandoned the technocratic model. One of the most commonly articulated alternatives is what has come to be known as the 'decisionist' model, as represented in Figure II below. On this model, policy is typically represented as based on 'sound science' but not on science alone. The decisionist perspective is, we contend, currently the dominant official orthodoxy in all the jurisdictions we studied.

\section{Figure II - The decisionist model}

\section{Science first, policy-making second}

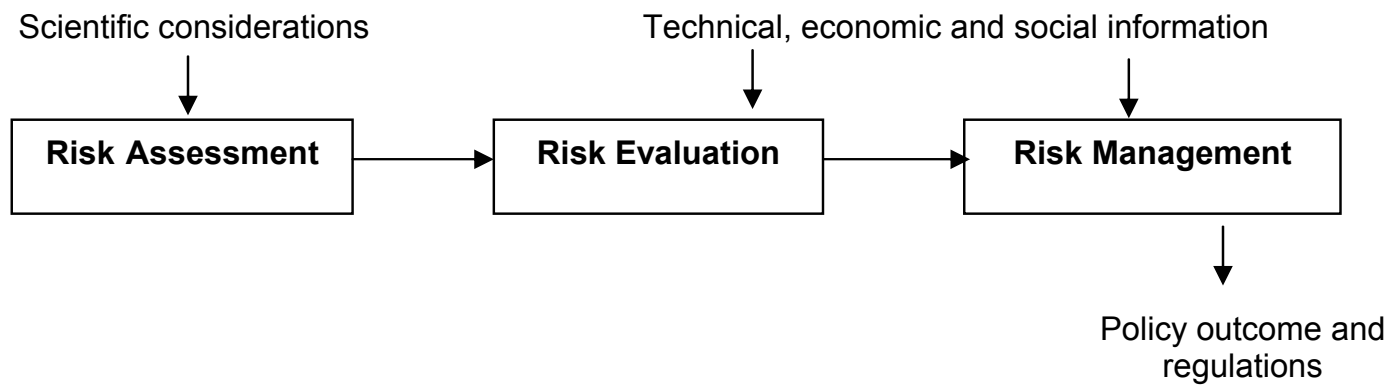

The 'decisionist' model, like the technocratic model, assumes in effect that science operates independently of its social, political, cultural and economic context. Nonetheless it also assumes that science alone does not provide a sufficient basis for policy decision-making. Rather, once scientific advice and judgements have been made social, economic, cultural and evaluative considerations are necessary to provide a 'down-stream' contribution to policy-making. For example, even if science could establish the existence, magnitude and likelihoods of some risks, policy-makers would also need to make judgements about whether those risks are acceptable, typically in exchange for some anticipated benefits. 
The model assumes, moreover, a clear division of labour between the scientific community, which is represented as assessing risks in a socially and ethically neutral way, and policy-makers who subsequently take legitimate account of the extent and distribution of the social and/or commercial benefits to be offset against the risks and their attendant uncertainties. On this model, expert knowledge, by itself, can never justify the prescriptive advocacy of any single policy.

The division of labour envisaged in this model is most frequently discussed in terms of a contrast between an up-stream activity called 'risk assessment' which is frequently represented as a purely scientific enterprise and a down-stream activity known as 'risk management' in which non-scientific considerations (often referred to as 'other legitimate factors', or OLFs) are taken into account. ${ }^{14}$

From a decisionist perspective, precaution is usually seen only as part of risk management but with no bearing whatsoever on risk assessment. It is a risk management judgement that can be made once a scientific risk assessment has been completed, and only if that assessment indicates important residual uncertainties. On this view, precaution enters into decision-making as part of the evaluative judgements that policy-makers need to make in order to decide how the conclusions of a risk assessment will influence policy decisions. When deliberating about whether, and how, to exercise precaution, policy-makers can deal with OLFs but those factors should not influence the questions addressed by the scientists nor the advice they provide. ${ }^{15}$ Precaution plays no role, on this model, in relation to either science or risk assessment.

The European Commission's Feb 2000 Communication on Precaution presumes a decisionist model of precaution. Precaution is, for the Commission, a legitimate response to scientific uncertainty. But the text of the document also seems to assume that risk assessments are entirely objective and neutral and that scientific risk assessments are not the kinds of judgements that could be more or less precautionary, and therefore precaution has no relevance to risk assessment. The Comments from the European Commission, 27 June 2000 to the Codex and OECD Ad Hoc Group on Food Safety similarly adopts an orthodox decisionist model of: “...the precautionary principle...[which] ...is nothing else than a risk management decision that provides that the lack of full scientific evidence does not prevent the decision-maker from acting...” (p. 3) (emphasis added)

Evidence that decisionist models are being invoked has been provided by several recent developments. These include the publication, in the UK, of the Guidelines on 'The Use of Scientific Advice in Policy Making', Office of Science and Technology. ${ }^{16}$ The British government's Chief Scientist argued, for example, that: "Scientific advice is only one element among the considerations which may have to be taken into account, and which might include social, political, economic, moral or ethical concerns. [Policymakers]...will need to judge how and at what stage the scientific and other concerns are to be brought together in the decision making process." "These "other concerns", the OLFs, have been evolving in response to changes in perception of risks; acceptability varies over time. ${ }^{18}$ 
During our interviews, officials in several jurisdictions argued for example that: "The decision making process is a two-tiered process. Science comes first but it is followed by a consideration of other legitimate factors." One interviewee even articulated the classic phrase of 1970 s science policy: "Science is on tap not on top."

A member of the UK's Advisory Committee on the Release to the Environment (or ACRE, a body that provides science-based risk assessments and policy advice) represented the committee's judgements as entirely scientific and defended that view by arguing that ACRE is an expert committee, and that the only expertise the members have is scientific, therefore their judgements only involve scientific considerations. ACRE is responsible for advising ministers on applications for consent to introduce novel organisms into the environment. The individual pointed to other institutions with explicit responsibility for non-scientific aspects of risk policy-making. Not only do ministers have such responsibilities, but they also receive advice from a separate body known as the Agriculture and Environment Biotechnology Commission (AEBC) that is expected to provide advice on the social and ethical dimensions of policy on the introduction of novel organisms. Indeed, in the interviews almost all experts and officials asserted that, within their own jurisdictions, science and politics were never allowed to contaminate each other.

A decisionist perspective provides more resources with which to explain interjurisdictional disputes than a technocratic one. As one Commission official explained: "Once there is scientific uncertainty, you can arrive at different decisions in different jurisdictions, starting with the same uncertainty, because the values are different [in different societies]."

The Codex Alimentarius Commission also assumes a decisionist paradigm, as indicated for example by the assertion that there is: “.... a functional separation of risk assessment and risk management." ${ }^{\text {"19 }}$ Similarly, an official at the WTO sought to explain disputes by reference to the non-scientific aspects of decision-making, saying: "It is not just about science, but also about what level of risk is acceptable. We can have different decisions in different jurisdictions, as long as the procedure is transparent and there is consistency. But the problem is that [some] countries don't define clearly what their acceptable level is, they just say "very low"”.

The remits of the food regulatory authorities in several jurisdictions are, however, ambiguous. In the USA, the FDA is responsible for both risk assessment and risk management, for both the scientific and the political aspects of risk appraisal and decision-making. In the UK, the new Food Standards Agency, like the FDA, has responsibility for both the risk assessment and risk management decision-making. In France on the other hand, the Agence Française de la Sécurité Sanitaire des Aliments (AFSSA) has responsibility primarily for risk assessment but not for risk management. ${ }^{20}$ Even where these institutions adopt similar forms of words to describe and circumscribe their responsibilities, they do not always interpret those expressions in identical ways.

If policy decisions are seen as the joint product of science and 'other legitimate factors' there is a risk, in the eyes of some protagonists, that policy-makers might 'meddle with the science'. Several interviewees argued, for example, that problems of that kind had arisen in the context of the BSE saga. As one British official explained, when the 
Permanent Secretary at the Ministry of Agriculture told the chairman of its expert advisory committee that the scientists should not provide any advice that would entail any increase in public expenditure, he was trying to apply inappropriate political influence on a set of scientific deliberations. ${ }^{21}$ The expert committee withstood, at least to some extent, that pressure, but the underlying problem that scientific representations of risk might be compromised by their economic and political context was often emphasised, but it was widely argued that giving institutional independence to expert scientific advisory bodies, and ensuring procedural transparency provide the best possible guarantee against inappropriate 'meddling'.

Within a decisionist framework, one official argued, for example, that “...benefits should be subject to analysis as rigorously as risks, and taking into account the riskbenefit balance should be explicitly allowable in international trade negotiations. Thus, risk-benefit analysis should be formalised." Similarly, in France an official report on Precaution argued that what was needed is a 'second circle' of expertise, which would include economists, social actors and representatives of the public, whose remit would include carrying out a social and economic risk-benefit assessment. ${ }^{22}$ On that model, risks are assessed by experts in the first stage, but at the second stage benefits are also assessed, and then juxtaposed to the product of the first stage.

A senior British official, making orthodox decisionist assumptions, remarked that: " ...a risk assessment cannot be precautionary; but a decision based on that information may be more or less precautionary." That individual expressed confidence that the adoption of precaution would not change the nature of risk assessment, but might imply the adoption of additional precautionary safeguards such as the post-release monitoring of the relevant products. 


\subsection{Our analysis - the 'transparent' model}

Our comparative analysis of the three disputes and five jurisdictions suggests, however, that neither of the two models favoured and invoked by the vast majority of our interviewees was sufficient to explain the nature of the disputes. A decisionist model provides some resources with which to understand some aspects of inter-jurisdictional disputes, but it remains difficult from such a perspective to explain why different groups of expert advisors provide incompatible risk assessments, without assuming that some or all of the competing assessments are shoddy or politically biased. Our analysis suggests however that a different, or third, model of the role of science and OLFs in risk appraisal and decision-making is required to provide the resources with which to comprehend the key aspects of the disputes and policy-making processes more generally.

The transparent model differs from both of the antecedent models by assuming that risk assessments are framed in some important ways by their social and policy contexts. From this perspective, it is misleading to represent policy-making as divided into a purely scientific up-stream risk assessment phase followed by a down-stream risk management phase. In this model, scientific risk assessments are seen as framed by legal requirements and by social, economic and political judgements, and those upstream assumptions therefore contribute to setting the agenda of the scientists responsible for risk assessment. Those judgements concern, for example, the objectives of policy, which effects are deemed to be 'risks' or 'adverse effects' and what counts as relevant evidence. They consequently set the agenda for scientists to deliberate and this explains in large part how different scientists can reach differing risk assessments.

The last 15 years have witnessed intensive efforts on the part of science policy officials and scholarly analysts to comprehend the role of science in public policy-making, and our research indicates that a growing proportion of senior officials are articulating what we refer to as a 'transparent' of science in policy-making; and that model is represented graphically in Figure III on page 26.

Our use of the term 'transparent' is not intended to suggest that current practices transparently fit this model, but rather to suggest that if they were transparent, they would be seen as operating in accordance with this model. 


\section{Figure III - The transparent model}

\section{Reciprocal links between science and policy}

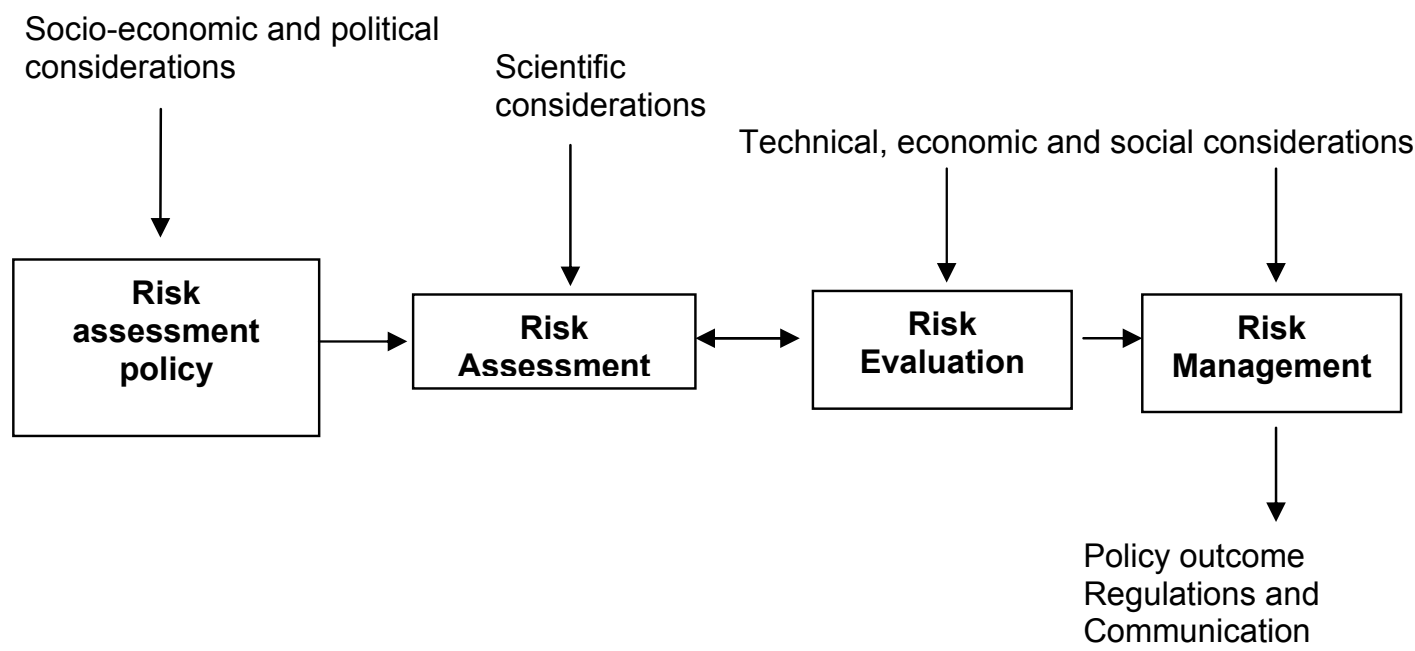

The distinctive feature of this model is that it not only assumes that policy decisions involve social, economic and political judgements in the context of downstream tradeoffs, but it also see scientists as operating within specific social, political, cultural and economic contexts that can affect the agendas, contents and conclusions of their risk assessments. When the Codex Alimentarius Commission articulated the case for acknowledging the importance of what it refers to as 'risk assessment policy' it was highlighting the importance of what, in the context of this model, can be termed 'upstream' framing assumptions. Those assumptions play a key role in setting the agendas of scientific deliberations and framing their deliberations.

This analysis, and model, does not assume that the incorporation of social, economic and political considerations into risk assessments renders them 'un-scientific'. It assumes that risk appraisal is typically a hybrid enterprise and therefore indicates the possibility of, and scope for, addressing such considerations more explicitly and opening them to evaluation and negotiation.

This model does not entail that politics illegitimately meddles with science, but indicates rather that risk managers may, and perhaps should, take responsibility for risk assessment policy judgements that circumscribe the scope, or at least the minimum scope, of the risk assessors' deliberations. Historically, in circumstances when the importance of risk assessment policies was not acknowledged, the scientists responsible for assessing the risks were left to rely on their own assumptions and intuitions, and those assumptions may have been neither transparent nor legitimated. 
The transparent model also does not entail that risk managers can or will routinely prejudge the conclusions that the risk assessors will reach. It implies rather that risk managers may properly take some responsibility for indicating the range of issues that they deem important. Policy-makers are not expected to tell the expert risk assessors which conclusions they should reach, but rather to indicate clearly which are the specific risks that they particularly want assessed.

According to the transparent model, precaution can be understood as a consideration that can be invoked not only as part of the set of downstream judgements, as in a decisionist model, but also as part of the set of 'upstream' judgements that frame the scientific assessments of risk. From this perspective, different groups of scientific risk assessors may reach different conclusions, and do so because they have adopted different risk assessment policies and consequently framed their deliberations within different and divergent sets of upstream assumptions. If the framing assumptions of scientific risk assessments can legitimately differ, then different groups of scientists may be focussing on slightly different agendas, and those factors help explain how and why they reach differing conclusions. They are often not just offering competing answers to one shared set of questions, they are responding to somewhat different sets of questions. That is not the only reason why disagreements occur, but it is a source of disagreements that has not yet been sufficiently appreciated.

A transparent model seems not only to be explicitly articulated in the science policy literature, and in the comments of a growing fraction of key officials, it is also emerging in official documents. For example, the UK's Health and Safety Executive argued in its 2001 report on Reducing Risks, Protecting People that: "Even using all available data and best science and technology, many risk assessments cannot be undertaken without making a number of assumptions such as the relative values of risks and benefits or even the scope of the study. Parties who do not share the judgmental values implicit in those assumptions may well see the outcome of the exercise as invalid, illegitimate or even not pertinent to the problem."23

The introduction of the concept of 'risk assessment policies', especially at the Codex Alimentarius' Committee on General Principles, provides a powerful indication of a growing recognition of the existence and importance of these judgements. The Codex Alimentarius Commission's draft working definition of 'risk assessment policy' (at step 5 of its 8-step procedure) states that:

"Determination of risk assessment policy should be included as a specific component of risk management. Risk assessment policy should be established by risk managers in advance of risk assessment, in consultation with risk assessors and all other interested parties. The procedure aims at ensuring that the risk assessment process is systematic, complete, unbiased and transparent... Where necessary, risk managers should ask risk assessors to evaluate the potential changes in risk resulting from different risk management options." 24 (emphases added)

Those remarks are difficult to comprehend other than in terms of the transparent model because they portray the science of risk assessment as conditioned by up-stream risk management agenda-setting judgements and then modulated by down-stream risk evaluation judgements. 
When the Codex draft says: "Risk assessment policy should be established by risk managers...in consultation with risk assessors and all other interested parties..." there is an implicit acknowledgement that those risk assessment policy judgements gain their legitimacy by virtue of the extent to which the deliberative process through which they are decided is accountable. A similar perspective has emerged from the European Community's Joint Research Centre which has stated: "Public inputs to policy debates are not merely 'opinions', but may be relevant knowledge, values or questions which scientists have neglected. There needs to be a long-term process of mutual learning between the public and science, which will necessarily involve new institutional relationships and forms. This will require deliberate experiments in the design of new hybrid institutions and roles., ${ }^{25}$ (italics in original) 


\section{Competing framing assumptions and competing assumptions about framing}

While those three models provide some descriptive and analytical tools, they do not capture all the relevant features of the understandings and assumptions that prevail within the jurisdictions we examined. They suggest, however, that jurisdictions (and protagonists within jurisdictions) may adopt contrasting views about a range of other key variables, including the ways in which relevant risks are defined and about how the appropriate scope of risk assessments can be decided.

\subsection{Definitional framing issues}

To the extent that up-stream agenda-setting judgements have been addressed explicitly in official documents, and sometimes discussed in terms of 'risk assessment policies', they have primarily been concerned with what we have referred to as 'definitional framing issues'. Those are concerned with decisions about the definition of what count as risks and the scope of risk assessors' deliberations. This section discusses current regulatory practices, and protagonists' views, in relation to such definitional framing issues, whilst the subsequent section will explore a further set of framing issues concerned with procedural and evidential judgements.

Historically there has been some evidence of a process of evolution from an early stage at which judgements about up-stream agenda-setting judgements about the scoping of risk assessment were made either discreetly or they were represented as if they were objective and neutral scientific judgements. Subsequently, as those judgements came to be increasingly contested, they tended to become more conspicuous, and consequently in greater need of legitimation. There remain, however, significant differences between jurisdictions.

In the context of the discussion about rBST in the USA, for example, changes to the incidence of mastitis in treated cows have been represented by the US risk assessors and policy makers as being problems of 'herd management' rather than risks to veterinary health. Similarly, a common view among members of the European scientific advisory committees dealing with GM crops was that the development of pest or herbicide resistance was not an environmental risk but an agricultural management problem. Assumptions were therefore being made about the evolution of the entire agricultural production system, but they were not open to scrutiny or debate. Subsequently, these implicit assumptions were highlighted and challenged through the public controversy surrounding GM crops. That controversy might in turn have resulted from a public reaction to the imposition of such un-negotiated and unaccountable socio-economic assumptions. They are increasingly being discussed, contested and defended explicitly.

In our research we found clear evidence that jurisdictions are increasingly addressing up-stream definitional framing issues in explicit rather than implicit ways. For example, the revision of the European Directive 90/220, and its replacement with Directive 2001/18 on the Deliberate Release into the Environmental of Genetically Modified Organisms, indicates that there was widespread recognition in the European Parliament, and at the Council of Ministers that it was desirable explicitly to extend the scope of EU risk assessments of the release of GM crops from a relatively narrow focus 
on direct and short-term effects to a broader perspective that includes long-term and indirect effects.

The establishment and conduct of farm-scale trials on GM crops within the EU also indicates that issues concerning the potential environmental consequences of changing crop management practices are now explicitly deemed as legitimate parts of the experts' risk assessment agendas. Their introduction followed an explicit shift in risk assessment policy, which in effect revised the agenda for scientific deliberations.

We did, however, find competing interpretations of some of the revisions to the environmental release Directive. While most protagonists interpreted the revisions as constituting an explicit shift in risk assessment policy, national officials in several EU Member States argued that expert advisors in EU Member States always had scope to consider long-term and indirect effects, but now their freedom to do so is being made explicit rather than being left implicit. Some members of expert advisory committees challenged that interpretation, however, arguing that they had sometimes previously been told by their secretariats that indirect effects were beyond the scope of their remit.

At least two other explicit attempts to come to grips with key aspects of risk assessment policy have recently emerged in relation to the environmental release of GM crops. In the UK, both the UK's Advisory Committee on the Release to the Environment (ACRE) and the Agriculture and Environment Biotechnology Commission (AEBC) are preparing to publish discussion papers on how the concept of environmental 'harm' should be interpreted.

The remit of the AEBC is slightly vague. It is: “...to provide...independent, strategic advice on developments in biotechnology and their implications for agriculture and the environment. It will look at the broad picture taking ethical and social issues into account as well as the science." ${ }^{, 6}$ There are at least two directly conflicting interpretations of that remit, one that fits in a decisionist framework and the other that presupposes a transparent model. On the first view, the AEBC modulates the scientific advice from ACRE, once it has spoken, but has no role to play influencing the risks that ACRE assess, nor the manner in which they are assessed. From a transparent perspective, the AEBC may comment not just on the social and ethical aspects on following the advice of ACRE, but also on the risk assessment policy that ACRE should and does adopt. Both of those interpretations were evident from the comments of various experts and officials in the UK.

Directive 2001/18 refers to 'harmful effects', and in recent years it became increasingly evident within ACRE that the interpretation of the concept of 'harm' is contestable and contested, and that the issue needed to be clarified. Some members of both expert advisory committees have suggested that the concept of harm could be interpreted as implying that any environmental change to flora and fauna could count as harm, while others argue that harm should be interpreted as a significant change to the population of a vulnerable or endangered species. People are, however, interpreting 'significant' 'impact' 'population' 'vulnerable' and 'endangered' in differing ways that depend, in part, on their values. There is disagreement as to whether it would matter if the population of some species were eradicated in one environment, just so long as they survived in other environments, or even in one other environment. Some expert advisors 
have argued that any animal that eats commercial crops is a pest and could be eradicated. Others argue that some non-zero level of such insect and bird populations in agricultural areas can and should be accepted and protected.

As well as those types of disagreements about the interpretation of harm, there are differences on the question of where responsibility should lie for deciding what is to count as harm. Some members of the AEBC argued that it should be for ministers rather than scientific advisors to decide, while others propose to locate that responsibility with scientific expert committees. It was noticeable, in particular, that officials responsible for advising ministers tended to think that the scientists should decide what counts as harm, while several scientists wanted guidance on that issue from ministers and their officials.

The debates within and between ACRE and the AEBC (and analogous discussions in the USA and other EU Member States) over what environmental changes should be counted as harmful can readily be interpreted as a discussion about risk assessment policy, and about the assumptions that should frame the risk assessment that ACRE is expected to provide; and that is indeed how the majority of participants now seem to be interpreting those debates.

In the USA, in the late 1990s, evidence emerged of debates about up-stream definitional framing assumptions, and policies for the assessment of the risks of GM crops, even though the debate was not couched in those terms. A report of the Scientific Advisory Panel (SAP) of the US EPA said: “... it is disappointing and perplexing that the [EPA] failed to follow through and address the questions its personnel identified in the 1980s. These same questions now appear to be emerging issues, i.e. monarch butterfly and $\mathrm{Bt}$ corn... [In our meeting] there were several discussions regarding the lack of certain test protocols and/or scientific data to justify new or expanded sets of test data from registrants..., 27 Those remarks indicate that the EPA's SAP drew attention to some of the definitional framing assumptions that the EPA had adopted, and the ways in which they had changed, while the EPA itself was more reluctant to do so explicitly. Subsequently, it has become increasingly difficult for the US authorities to avoid explicit debates on those issues of risk assessment policy.

In the USA in January 2000, the US Department of Agriculture asked the US National Research Council (NRC) to examine "...the scientific basis for and operation of APHIS [the Animal and Plant Health Inspection Service] regulatory oversight..." of transgenic crops. ${ }^{28}$ The report was produced by NRC's committee on Environmental Impacts Associated with Commercialization of Transgenic Plants. It used language that evidently struggled to be diplomatic, but it is nonetheless highly critical of the way in which APHIS had been assessing the environmental risks of releasing GM crops. It argued that the rigour and thoroughness of APHIS's reviews had improved since 1990, but nonetheless argued that APHIS's risk assessments needed to become more rigorous, more detailed, and most importantly in this context, broadened in their scope. ${ }^{29}$

The NRC committee, for example, found that APHIS habitually assumed that the risks associated with the introduction of genetic novelty are related to the number of genetic changes and the origin of the novel genes. ${ }^{30}$ "The committee compared empirical evidence of environmental impacts involving small to large amounts of genetic 
novelty... and found no general support for this assumption. More specifically, it was found that (1) small and large genetic changes have had substantial environmental consequences; (2) the consequences of biological novelty depends strongly on the specific environments into which they are introduced; (3) the significance of biological novelty depends on societal values..." ${ }^{, 1}$ (emphasis in the original)

The NRC provided a remarkably frank and vigorous critique of both the strategy and the tactics of the risk assessments that APHIS has been providing. It argued, as had other commentators, that in practice, the definitional framing assumptions of APHIS's risk assessments had been widened during the 1990s, but argued that they should be significantly wider still; in short the Committee recommended fundamental changes to APHIS's risk assessment policy. It would, however, be premature to forecast the outcome of the resultant discussions in the USA. In the preface, the Chair of the committee states that following much deliberation, the committee members came to the consensus that "While risk of environmental effects can be defined simply as a multiple of hazard and exposure, the measurement of both hazard and exposure involves a complex blend of ecological and social factors."

It is nonetheless evident that at least some key protagonists in the USA, including a large fraction of influential scientists, believe that official risk assessments are framed by a group of agenda-setting socially-based assumptions, and that those assumptions can and should be changed, and changed by making them broader and deeper. That suggests that there is some implicit but strong support for a transparent perspective in the USA, especially in NRC, and that the definitional framing assumptions of US risk assessment of the release of GM crops may change in the foreseeable future.

Within the EU, there is a lively debate underway into how the provisions (in Annex VII) of Directive 2001/18 concerning post-release monitoring of GM crops should be interpreted. The Directive indicates that such monitoring should be designed to check that any assumptions made in the course of risk assessments are actually valid. This general requirement has been interpreted in various ways. Some, for example, interpret it as recognising that some relevant uncertainties cannot be adequately resolved before commercial use is permitted. Others argue that it also means that a sufficiently comprehensive assessment of safety might, in some cases, justify not imposing a requirement for such monitoring.

The debate about post-release monitoring can be most readily interpreted from a transparent perspective that sees non-scientific considerations entering risk appraisal and decision-making processes both before and after scientific risk assessments are conducted.

Our interview findings indicated that, in practice, the scope and framing of risk assessments of GM crops has been, and is being, extended in the USA, the UK, in France, Austria and at an EU-wide level; and those findings are consistent with published analyses in the science policy literature. ${ }^{32}$ While a process of that type has been occurring in relation to GM crops, a similar process has been occurring with beef hormones and with rBST. In the early 1990s, the environmental fate of hormones secreted by farm animals was outside the scope of European risk assessments, but in the late 1990s their scope was broadened in that direction. In the early 1990s, official 
discussions of the potential risks of rBST tended to focus on the possible consequences for human consumers of milk and dairy products. During the 1990s, however, the scope of those assessments was noticeably widened to focus more specifically on issues of animal health. The main difference in this regard is that, in the case of GM crops, the scope of risk assessments seems still to be widening, although the scope of US and European assessments do not yet coincide. In respect of the other two case studies, the scope of those risk assessments have also widened (on both sides of the Atlantic) though the incremental steps by which they have widened have been comparatively modest, yet US-European differences remain.

There is some evidence that a transparent perspective is developing amongst at least some leading officials at the WTO, although those developments are more implicit than explicit. A WTO official pointed out that: “...science is referred to in the SPS, TBT and DSU agreements, but was most detailed in SPS...science was seen (by other WTO officials, Panels, and the Appellate Body) as a way to 'test a measure', but science was not delivering the results which had been anticipated, because science was "not as certain' as had been envisaged, and did not give 'black and white' answers." On that account, officials had been observing (and been surprised) that scientists challenged other scientists and that sometimes minority scientific opinions needed to be taken into account. The official commented: "All of this is very new to us, and we are struggling to deal with it... Understanding the nature of science is a key issue at WTO." 


\subsection{Procedural and evidential framing assumptions}

The discussion above focused on framing issues concerning the ways in which risks comes to be defined and on decisions about the appropriate scope of risk assessments. In the course of our study several other important issues emerged that constitute framing issues, but that are concerned more with judgements about the procedural and evidential requirements of risk assessments than with definitional questions. Those types of issues tend not to be articulated as explicitly in official documents and statements of 'risk assessment policy' than what we have called definitional framing issues. They have, however, been made explicit, and are partially recognised within trade disputes and by some of our interviewees and they are discussed in this section.

\section{2.1 Symmetry}

One focus of our inquiry was on the question of whether the evidential requirements for approval of product are, or are perceived to be, more or less stringent, or exactly the same, as those for decisions to restrict such products. In other words are the evidential requirements symmetrical or asymmetrical?

Another aspect of symmetry concerns symmetry of treatment such as the degree of critical scrutiny that is applied to studies that provide prima facie evidence of either safety or risk? If evidence from studies purporting to indicate a risk is scrutinized more critically than evidence from what are termed 'negative' studies (i.e. those that show no evidence of harm) then the approach is not particularly precautionary, whereas if the experts are more concerned to avoid false negatives than false positives then that approach would be correspondingly more precautionary.

In order to answer those questions we tried to establish whether individual jurisdictions adopted a uniform and consistent approach across different kinds of regulatory decisions and through time. We assumed that we might be able to identify consistent patterns characteristic of particular jurisdictions, and would then be able to make interjurisdictional comparisons. In practice what we found was that we were unable to identify consistent uniform practices within those jurisdictions. For each jurisdiction, we could find examples of symmetry and asymmetry, and those examples of asymmetry were asymmetrical in both directions.

The one consistent underlying pattern that we could discern was an overall tendency to, what can be termed, 'policy inertia'. In other words, it often emerged that significantly more evidence would be required to change policy than to continue with the existing policy, irrespective of the initial direction of those policies.

As one expert advisor said: "...to ban something that is already allowed is very difficult. You have to have strong evidence, and probably stronger evidence that had been required when it was permitted in the first place. Committees typically assume that all existing judgements are sound. Committees therefore need not re-evaluate the old evidence, but actually focus on new evidence. Consequently, the benchmarks shift over time." 
Several expert advisors also agreed that "...once a product has been marketed, it become possible to look, epidemiologically, at actual patterns of usage, and at possible consequences, which typically is not the case for new consents." That highlights the fact that post-marketing surveillance might reveal evidence that would not have been accessible to an anticipatory risk assessment, and therefore could not have been assessed, critically or otherwise. Since, however, post-marketing surveillance is at a very rudimentary stage, dependent on scarce skills and resources, and applied only in homeopathic doses, it is not surprising that interested parties take advantage of the opportunities for representing the absence of evidence of harm as if it provided evidence of the absence of harm.

Policy inertia can occur for a variety of reasons. For example, once consent has been granted to the marketing of new products the sponsoring companies will have few incentives to conduct further studies to test their assumptions about the safety of those products, and public resources are not being used for such purposes either. While some regimes require some post-release monitoring of selected products such as pharmaceutical formulations and genetically modified crops, the implementation of those surveillance systems may be imperfect. Some expert advisory bodies and risk management institutions may, moreover, be reluctant to review or accept the implications of new studies that cast doubt upon their previous advice, judgements or decisions. Institutional rigidities are features of many organisations, even in the field of risk appraisal and decision-making where flexibility and a readiness to learn may be thought to be especially important.

When asked about the extent to which the expert advisory committees were alert to the possibility of encountering false negatives and false positives, there was a remarkable consensus that, under current conditions, experts are more likely to subject an apparently positive finding of evidence of a risk to a thorough critical scrutiny than to a study apparent indicating no evidence of a risk. One commentator argued that, by analogy with a court of law: "...official scientists think of a false positive as a more grievous failing than a false negative, while a precautionary approach puts it the other way round."

The asymmetrical treatment of negative and positive studies appears to be increasingly recognised as important by scientific experts. The 2002 NRC report states, for example: "The committee recommends that APHIS should not use the term 'no evidence' in its environmental assessments. The term 'no evidence' can mean either that no one has looked for evidence or that the examination provides contrary evidence. Lack of evidence is not typically useful in making regulatory decisions about risk." 33 If that is a mistake then it is one that has frequently been made.

When evidence emerged from the studies by Hilbeck et al that Bt crops might adversely effect populations of lacewings, several jurisdictions asked their expert advisory committee to critically review studies purporting to show adverse effects, but they were not specifically asked to subject to a similarly critical scrutiny studies not showing any evidence of adverse effects. ${ }^{34}$ It is noteworthy therefore that Hilbeck and colleagues did provide a critical scrutiny of negative evidence, but there was little to indicate that European advisory committee took that into account. ${ }^{35}$ Greater institutional care was taken to try to avoid false positives than to avoid false negatives. That implies that 
critical scrutiny has been applied in an asymmetrical fashion that prima facie seems difficult to reconcile with a precautionary approach.

\section{2.2 Use of Direct/Indirect evidence in assessments of risks and benefits}

Another key issue, especially in the light of the adjudications in the beef hormones case, concerned just how direct scientific evidence needs to be and just how indirect it may be. In the WTO dispute over beef hormones the main reason why the adjudicators found for the plaintiffs was because the evidence cited by the EU was, in effect, deemed to be insufficiently direct, derived as it was from studies of people directly exposed to hormone rather than to meat from animals treated with hormone implants. The WTO Appellate Body stipulated that, to provide the scientific basis for a trade-restrictive measure, the evidence adduced must be 'specifically focussed' on the risk that the measure aims to control. The adjudicators agreed with the EC, however, that the evidence it adduced concerning non-compliance in the USA with regulations governing the use of hormones implants was relevant because the risks being assessed were those directly arising from their agricultural use rather than those which could be indirectly inferred from experimental protocols that might not provide a sufficiently direct representation of actual conditions.

Officials at the European Commission enthusiastically cited the conclusions of the Appellate Body in the beef hormones case that recognised that risk assessments should reflect the 'real world' (rather than just the laboratory) but they adopted a slightly different approach in relation to the assessment of the release of GM crops. In that context, all the data prior to the conduct of field trials and/or commercial releases are inevitably indirect; they had derived from prior contained use in artificial environments.

Similarly, expert advisory committees are increasingly acknowledging that evidence from small-scale field trials, that have been conducted taking steps to prevent or contain potential risks, provide very little useful evidence for the risk assessment of large-scale commercial practices. This is partly why larger-scale field trials, more closely reflecting 'real life' have been initiated, in France and UK at any rate. Those examples suggest that in some circumstances risk appraisal and decision-making are inevitably based on indirect evidence yet if the evidence is too indirect the resulting risk assessments will fail the test of WTO compliance.

In the UK, ministers have provided their expert advisory committee ACRE with some risk assessment policy guidance on such an issue: "Where a large body of literature exists for a similar crop, it may be sufficient to perform only as much experimental work as necessary to demonstrate that the literature is applicable to the new crop. For example, the current farm-scale evaluations of glufosinate tolerant oil-seed rape may be to a greater or lesser extent relevant to glyphosate tolerant oil-seed rape. On the other hand, some additional experimental work may be required to compare the weed control efficiency of glufosinate and glyphosate." ${ }^{36}$ The British government therefore assumes that the use of indirect evidence should, in some circumstances, be deemed sufficient to permit the introduction of a novel GM crop, and that approach may be consistent with the provisions of Directive 2001/18 and the SPS and TBT agreements, but it is not necessarily a scientifically rigorous or a precautionary approach. 
In the USA, the decisions to authorise both beef hormones and $\mathrm{rBST}$ were based substantially on indirect evidence. When the FDA approved hormone implants in beef cattle, it assumed that all the hormones that occur naturally in beef are safe for human consumers, without formally assessing them. That approach continues to predominate in the USA, even though some strong but indirect evidence has emerged in December 2000 indicating that the hormone $17 \beta$-oestradiol may be genotoxic, which suggests inter alia that US policy concerning the acceptability of indirect evidence is asymmetrical and is neither scientifically rigorous nor especially precautionary.

A senior US official argued that because “...the incremental exposure $[17 \beta-$ oestradiol]...is a drop in the bucket, relative to the natural variation, (...) we are not concerned" but also acknowledged that: "We assume that naturally occurring hormones are safe. Food is assumed to be safe unless shown otherwise, though we do no evaluation." The European authorities, on the other hand, have not deemed the indirect evidence that the FDA accepts to be sufficient. A licence to permit the introduction of hormone implants into EU cattle herds would require far more evidence, and far more direct evidence, than has been deemed sufficient in the USA.

In the rBST case, in the context of a debate about the impact of BST-use on the concentrations of the pharmacologically active compound IGF-1 in cows' milk, a senior US official said: "To investigate the effects of IGF-1, genotoxicity and carcinogenicity tests can be done on the endogenous form. We can't quantify every person's exposure, so we must use averages...However, there is no reason to suppose that the extra amount from rBST-milk has greater potency than the endogenous form, so we don't discriminate between them and see no significant difference in effect from the extra amount." (emphasis added) Many US and European skeptics about rBST are, however, critical of the untested assumption that exogenous IGF-1 will behave in the same way as the endogenous form. ${ }^{37}$

The approach by the US authorities to evidence concerning possible adverse effects of GM-Bt crops on lacewings and monarch butterflies was outlined above, but in this context it significant that those studies were discounted in the USA for being too 'indirect' even though the data by reference to which Bt-maize was authorised was similarly indirect. ${ }^{38}$ The EPA dismissed those suggestions of harm by introducing various assumptions - but those assumptions were criticised shortly after by the EPA's own advisory committee, and some were even refuted by subsequent evidence. ${ }^{39}$

The EPA's Science Advisory Panel (SAP) argued that the Hilbeck data were dismissed by the EPA by reference to standards "...that were not applied to all the work reviewed by the agency, and the Hilbeck work was singled out for an excessively critical analysis..." 40 The EPA responded by indicating that it will require more specific and direct evidence about causal pathways of potential harm as a basis for deciding whether to re-register Bt toxins in corn. The biotechnology industry in turn has responded by supplying such evidence. That suggests that judgements about how direct evidence should be, or how indirect evidence may be, change over time, even within one jurisdiction and in respect of one policy topic.

According to ACRE, the Hilbeck et al lacewing paper alone does not establish a case to justify an immediate ban on the cultivation of the Novartis Bt maize in the UK or to 
impose additional restrictions on the release of other Bt crops. ${ }^{41}$ A similar argument was explicitly made by ARCE concerning the monarch butterfly Bt pollen study, namely that it was not sufficiently direct. ${ }^{42}$ One senior UK scientific advisory summed up the ambiguity of the science by arguing that: "...evidence is always more or less direct" while another argued that "...with any new [GM crop] product release... evidence is always indirect... but ACRE tries to advance by small incremental steps." There is no consensus yet concerning how wide those steps may be, nor how far they have to reach before policy decisions can be justified.

The WTO Appellate Body has insisted that evidence has to be 'sufficiently focussed' if the risk assessment is to provide the basis for a trade-restrictive measure and that in the US-EC beef hormones dispute the evidence fell short of that requirement. Differences of view over what can be deemed to be 'sufficiently focussed' and 'direct' evidence remain amongst EU Member States and between the EU and the USA.

\section{2.3 Benchmark comparators}

The next key issue concerns the benchmarks by reference to which risks are to be comparatively evaluated. This is an issue that arises particularly starkly in relation to GM crops. In the USA and some EU Member States, GM crops have been judged to be acceptable if the environmental impact of their cultivation is no more adverse than that which occurs as a consequence of the cultivation of industrially produced commercial crops. One expert argued, for example that: “...ploughing destroys lots of nematodes but it is deemed acceptable. Spraying with atrazine kills some non-target species, but that is deemed acceptable..." implying that it would be unreasonable to evaluate GM-crop cultivation by reference to especially demanding benchmarks. In some EU Member States, officials and authorities argued that the impact of GM crops should be no worse than that which occurs as a consequence of the commercial cultivation of crops using integrated pest management regimes. Officials and expert advisors in a few Member States, and other stakeholders in many parts of the EU, have argued on the other hand that their impact should not be worse than that which occurs in organic farming. Those benchmarks differ, but the choice between them need not be arbitrary.

The approach being adopted in the USA is in a state of flux. The EPA has recently accepted arguments advanced by its own scientific advisory panel that: “...to provide the most accurate comparisons, an untreated control should always be included."43 That shift in policy was strongly supported by non-governmental organisations in the USA, and now US risk assessors are supposed to compare the environmental impact of GM crops with a range of different kinds of agriculture including organic farming as well as conventional agro-chemical based farming. The EPA has accepted that a non-chemical comparator for potential harm from Bt corn can be considered, while remaining flexible on the question of what might be counted as 'unreasonable adverse effects' vis à vis that norm.

The agrochemical comparator became contentious, partly because it rested on a false assumption that Bt maize would simply replace chemical insecticide usage. In reality, only approximately 5\% of US maize acreage had been sprayed with chemical insecticides against the European Corn Borer (ECB) before Bt maize was marketed, mainly because such sprays were not very effective. ${ }^{44}$ Once the acreage under Bt maize cultivation had expanded to approx. $1 / 3$ of US maize fields, - i.e., to several times the 
proportion that had previously been sprayed with chemical insecticides against the ECB. Consequently, in 2000 the US NRC proposed further field studies to determine the impacts of specific pest-protected crops on non-target organisms, by comparison to the impacts of both chemical and non-chemical methods that were then currently in use. ${ }^{45}$ The EPA's Scientific Advisory Panel made a similar request. ${ }^{46}$ A key debate therefore has concerned whether Bt corn cultivation is far more widespread than the agrochemical methods which pre-dated its availability, and a question posed was whether the crop had replaced (or exceeded) the prior use of agrochemicals. The use of a more stringent comparator reinforced pressures for more sensitive test methods to detect non-target harm.

In the UK, the ACRE Secretariat's published guidance states that: "The assessment of the risk of a GMO needs to be placed in the context of existing agricultural activities, whether non-GM or organic, and which also have the potential to cause adverse environmental effects. The baseline against which the risk of a GMO can be compared has been the subject of discussion in ACRE. All agricultural activities result in adverse effects on the environment, and there are serious concerns about farmland wildlife declines that have occurred during the last fifty years. With GMOs, it has been common to compare the risks of a GM crop with the unmodified crop. The Department of Environment, Transport and the Regions (DETR) and ACRE have commented that it is inappropriate to demand the absence of non-target effects from the use of GM crops, while tolerating them from the use of non-GM crops whether they are grown conventionally, organically, or in accordance with Integrated Crop Management (ICM) methods". ${ }^{47}$

Official UK policy states, moreover that: "Risks will be assessed relative to the range of current management practices for equivalent non-GM crops, and/or the crops most likely to be replaced by the new GM crop, and relative to relevant Biodiversity Action Plans (BAP)". 48 Since there are more organic farms in Austria than in the rest of EU, it is understandable that some officials and experts, especially in Austria, support the policy of using organic farming as the appropriate comparator for GM crops, although that fact alone probably does not account for the adoption of such policies or arguments.

The key point here, however, is that one of the reasons why inter-jurisdictional differences remain over the risk from, and acceptability of, GM crops is because different assumptions are being made about the benchmarks by reference to which judgements of risk and acceptability should be made.

\section{2.4 Compliance}

The next key issue concerns the extent to which risk assessors are making, explicitly or implicitly, assumptions about the regulatory compliance. Do they assess the potential (or even the worst-case) consequences of non-compliance? Do they assume that any rules that might be set, or that have been set, will be, or are being, obeyed? The contrast may be an important one because, in the case of BSE, the members of the UK government's Spongiform Encephalopathy Advisory Committee (SEAC) believed prior to 1995 that the risks of consuming British beef were acceptably low, but only because they assumed that the Specified Bovine Offals regulations were being fully 
implemented, and their reassurances were predicated on that assumption. ${ }^{49}$ Once SEAC learnt of the shortcoming in compliance they modified their risk assessments and advice to policy-makers. In the context of the France-UK dispute about the acceptability of imports of British beef to France, the duration of the restriction was in part justified by reference to the fact that French officials were unsure if all the regulations were being strictly applied in the UK.

In the USA, it would appear that risk assessments are typically framed by assuming that there is, or will be, full compliance on the part of US producers. That is evident in relation to beef hormones, rBST and GM-crops. On the other hand, when evaluating risks from imported products a slightly different assumption is often made, namely that compliance cannot be relied upon. In the dispute between the USA and the EU over beef hormones the US initially argued that full compliance by US producers could and should be assumed, but the WTO dispute adjudications stipulated that the EU was within its right to assess the actual, rather than the nominal, risks and so need not assume that US regulations were being fully enforced.

The US approach to rBST assumed, and continues to assume, full regulatory compliance. The US FDA does conduct some surveillance on milk samples testing for antibiotic residues, but they only test for those compounds that are legally permitted, on the implicit assumption that no others are used. Moreover, a senior US official indicated that the number of drugs approved for use in dairy cattle is 32 , according to our database, but that the main surveillance activity focuses on just 6 beta-lactams. A 1992 report for the US General Accounting Office indicated that the FDA tested for only 4 of the 82 animal drugs in common use, so the agency lacked a comprehensive strategy for monitoring their use. A scientist working for a US consumer group argued that the FDA spot-checked 500 samples per year for 12 drugs, mainly for the beta lactam antibiotics, but that this testing seems likely to miss many drugs in use. ${ }^{50}$ That surveillance strategy implies that the FDA presumes that non-compliance is rare and/or insignificant.

Historically, EU risk assessors on the Scientific Committee for Food, and other Commission advisory committees have also typically assumed full regulatory compliance by European producers except when specific evidence of enforcement deficits emerges. Once the European Food Safety Authority has been established, it will be interesting to see whether there is any change in that respect.

One distinctive change that occurred in France following the establishment of AFSSA was that a new policy was explicitly introduced, especially in relation to the microbiological safety of food, to assume that regulatory compliance will be imperfect, and introducing an extra safety factor to take some account of such imperfections. In the UK, the Food Standards Agency does not yet have an explicit policy on this matter although the issue is under review. At Codex, however, assuming full regulatory compliance remains entirely normal, that is to say when Codex sets residue levels it is assumed that full (or perhaps an adequately high level of) compliance will occur. 


\section{Summary and conclusions}

This report has analysed the role of science and politics in risk policy-making, through the lens of a set of three international disputes. This report aimed to provide an analysis of those disputes to clarify what it is that is in dispute, and the conditions under which the frequency and severity of those disputes might be diminished. We set out to explore the way in which science is used, represented and invoked in setting regulatory measures and the extent to which, and the conditions under which, science could contribute to resolving regulatory differences and/or consequent disputes.

The use and representation of science is crucial to an understanding of those disputes, especially because the text of many international agreements, and many influential commentators, have assumed that science can provide definitive information by reference to which disputes could be resolved. Yet, amongst a broad range of stakeholders there is a growing recognition that science, on its own cannot settle policy questions. One important response has been to invoke the principle and concept of precaution.

The report aimed to analyse the reasons for the occurrence and persistence of disputes and to identify the conditions under which such persistent differences may most readily be reconciled. A further aim of this report has been to clarify the extent to which, and ways in which, precaution has been interpreted, and to elucidate the conditions under which precaution can be a legitimate component of risk policy-making in the context of European and international regimes.

\section{Key findings}

One of the key findings of this study is that science does not, and cannot, on its own, provide uncontested risk assessments by reference to which the differences over alternative risk management policies can be reconciled. This finding is not necessarily a problem in itself. One key problem identified by this report has arisen because some policy officials deny, or do not explicitly acknowledge, the limitations of science for risk appraisal and decision-making.

Risk assessments are not purely scientific judgements, partly because of the uncertainties in the science; policy-making is inevitably open-ended. Uncertainties have not only meant that scientists have interpreted shared bodies of evidence in differing ways; scientists have also disagreed about which bodies of evidence are relevant when conducting risk assessments.

Notwithstanding the fact that competing scientific answers can often be provided to common sets of questions, disputes can also be characterised by different policy assumptions, for example about which kinds of effects are within the scope of their deliberations, which effects are deemed to be significantly adverse, and therefore which questions the scientists should be expected to answer.

An agreement amongst Member States of the EU and the WTO to rely on scientific risk assessments to settle disputes over regulatory measures will, consequently not be 
sufficient to avoid or to reconcile such disputes. The disputes are not solely about scientific issues, and when scientists reach contrasting conclusions this can occur because they are addressing different questions, and making different assumptions about risk assessment policy issues, and not just because they are providing competing answers to a shared set of questions.

Unless and until there are explicit negotiations, and agreements, amongst different jurisdictions about the scope of risk assessments, how to take into account uncertainties and, more generally about risk assessment policy, then divergences in judgements about risks will remain remarkably difficult to reconcile.

If the principle of precaution is to be used in ways that are legally justifiable and scientifically and socially legitimate, then the evidence suggests that at least three conditions have to be fulfilled. Firstly, there have to be democratically acceptable ways of setting and/or legitimising risk assessment policies, particularly the pivotal issue of selecting the scope or boundaries of risk assessments. Ceteris paribus the more stringent the 'level of protection' (for whatever reason), the greater will be the uncertainty about whether or not a product or process could cause harm that exceeds such a norm, with consequences for the ways in which assessments of risks are conducted. Secondly, there needs to be some scientifically established uncertainty, of a sort that is relevant to the chosen level of protection. Thirdly, precaution is only appropriate in relation to hazards for which there are some prima facie empirical grounds, or theoretical reasons, or both, for anticipating possible adverse effects.

\section{Key findings from case studies}

In both the beef hormones and the rBST cases, the differences in the judgements and policies in the EU and the USA have arisen not just because different answers have been given to a common set of questions, but also because different questions are being asked, since conflicting judgements are being made about precisely which topics, processes and effects require scientific assessment. In both cases, the scope of official European assessments have been significantly wider than the corresponding US assessments, although there have also been differences within Europe.

The case of GM maize reinforces that conclusion but it also shows that not only are there now significant differences between Europe and the USA but also, that risk assessment policies have been changing, and changing quite rapidly in recent years within all the six jurisdictions. Those changes have entailed that the scope of risk assessments of the environmental release of GM crops has widened rather than narrowed. Policies have evolved, not so much because scientists have been giving changing answers to an unchanging set of questions, but because the range of effects they have been asked to assess has grown in scope and complexity.

Those changes in risk assessment policy have, moreover, occurred mainly for social and political reasons, which can be entirely legitimate in democratic terms and consistent with the provisions of WTO and EU agreements.

The fact that risk assessment policies differ and evolve, and contribute to the occurrence and persistence of disputes, can most readily be understood from what has been termed a 'transparent' perspective. From this perspective, the science of risk assessment and 
the perspectives and policies of risk managers have mutually influenced each other; neither independently determines policy outcomes.

Within and between the jurisdictions in which we conducted our research, we found a broad range of views about the role of science in risk assessment and risk management policy-making. To a useful first approximation, however, that range of views fell within two broad categories.

The first view, which we term a 'technocratic' approach' assumed that policy should and can be decided solely by reference to scientific considerations and expert advice. On that view policy should be based on, and only on, 'sound science'. From this perspective, the concept of precaution can be difficult to comprehend. If one assumes that the scientific basis for decision-making is sound and sufficient, then precaution appears otiose and irrelevant. Alternatively, policy can be said to have been made in a precautionary fashion just because risks are assessed in an anticipatory rather than a reactive fashion. The US government has argued, for example, that it adopts a precautionary approach whenever it uses a positive rather than a negative list system, and whenever standards are set without waiting until overt harm has been shown to have occurred.

The technocratic point of view (which continues to have some currency in all jurisdictions) has considerable difficulty however accounting for the occurrence, persistence and characteristics of disputes. It is often invoked, however, not only for descriptive purposes but also for rhetorical and normative ones. Jurisdictions and their officials tend to invoke the technocratic model when they are trying to justify relatively un-precautionary measures especially in a dispute with those who are seeking to justify more restrictive measures. They typically claim that their standards are based on, and only on, 'sound science'.

A second view, which we term a 'decisionist' model, assumes that regulatory policy is the product of a two-stage process, the first of which is purely scientific and is often called 'risk assessment'. At the second stage, the scientific risk assessment is supplemented by non-scientific social and political considerations, which also contribute to policy decisions. The 'decisionist' model is found very widely in all of the jurisdictions we have examined, and perhaps represents the prevailing orthodoxy. It assumes, in effect as did the previous model, that scientific risk assessments are socially, economically, politically and ethically neutral, but also that science alone does not provide a sufficient basis for decision-making. The decisionist model assumes a clear division of labour between the scientific experts, who are represented as located up-stream, assessing risks in a socially neutral way, and policy-makers who subsequently take legitimate account of so-called 'other legitimate factors' (or OLFs) concerning for example the extent and distribution of the social and/or commercial benefits to be offset against the risks and their attendant uncertainties.

From a decisionist perspective precaution is understood as a non-scientific consideration that may be invoked if a scientific risk assessment has first been conducted, and if, but only if, that risk assessment identifies some residual uncertainty and only if there is also some prima facie evidence of a particular risk. If those conditions are satisfied risk managers (as distinct from risk assessors) may make 
judgements concerning steps that might be taken to avoid or diminish risks about which certainty and precision are not yet available. From this perspective, precaution is a factor that has no bearing on the content or conduct of risk assessments or scientific studies. Often, from a decisionist perspective, it is also assumed that precaution will only apply 'in the interim', until further research has diminished or eradicated the uncertainties.

The decisionist model provides more resources with which to understand the occurrence and persistence of trade disputes than the technocratic model, since different judgements can be made about the acceptability of risks or the trade-offs between risks and benefits, but our research suggests that it may not be sufficiently rich fully to comprehend the nature and complexities of these disputes.

The technocratic view pre-dated the decisionist view, but together those two sets of ideas have been dominant, though in contention with each other, over recent years. Since the mid-1990s, however, a third approach to science and governance has emerged in the work of senior policy advisors and science policy scholars. This third perspective, which we call a 'transparent' approach, provides a richer set of resources with which to understand inter-jurisdictional disputes. Our contention is that, although almost all public policy officials interviewed in the five jurisdictions invoked either technocratic or decisionist account of the disputes, those disputes can be more effectively analysed and explained by drawing on the resources of what we have termed a transparent model of science-based public policy-making.

The distinguishing aspects of a transparent model are that it assumes that the science of risk assessment will be necessarily and legitimately influenced by the socioeconomic and cultural context in which it is located. This approach assumes that nonscientific considerations (or OLFs) play a distinctive up-stream role setting the prior framing assumptions that shape the ways in which risk assessments are constructed and conducted. This approach helps to explain much of why regulatory disputes occur and why they persist, but it also suggests some of the conditions under which they may be resolved.

From a transparent perspective, precaution is a consideration that can apply both before and after risk assessments have been conducted. Risk assessments may themselves be more or less precautionary, in ways that may depend for example upon their scope and depth and the range of alternatives under consideration. Precaution may also be reflected in the extent to which, and ways in which, uncertainties are acknowledged, and the extent to which a broad range of sources and types of knowledge and expertise are involved. Precaution, on this model, is also a consideration for risk managers who have to make explicit judgements about the extent to which uncertainties (as well as the risks) may, or may not, be acceptable. Precaution is, from this point of view, a characteristic of both the process through which decisions are reached and the rules for making decisions.

While the technocratic and decisionist models captured many aspects of the statements of officials and key protagonists in the jurisdictions we studied, the transparent model more effectively explains how policies have been and are being made, and how and why 
they conflict; it highlights aspects of what the disputes are about, that the other two models fail to recognise or accommodate.

The empirical evidence that we have gathered and analysed suggests that, both within the EU, and when comparing the EU with the USA and the WTO, disputes have occurred and persisted because:

- different judgements have been made about what the breadth and scope of scientific risk assessments should be, and therefore about which uncertainties matter

- different judgements have been made about the ways uncertainties should be handled by risk assessors, and the significance that should be ascribed to them, and

- different judgements have been made about the 'chosen level of protection' i.e. the extent to which those risks and uncertainties are socially acceptable.

Even though there is a recognition, in some parts of all jurisdictions, that science alone cannot determine regulatory policies nor settle policy disputes, some protagonists in all the jurisdictions continue to represent the policies for which they are responsible as entirely science-based. Typically they argue that any competing risk assessments and/or policies are either less scientific than the ones adopted by their jurisdiction or they are simply un-scientific.

If policies were truly based solely on 'sound science' then there would be no scope for the exercise of discretion. Sometimes, this seems to be what policy makers seek: a rhetorical deference to 'sound science', as if this coincided with the advice from experts, even though that advice is typically informed by policy assumptions as well as scientific considerations. Recent events, however, have demonstrated that in cases where evidence of harm subsequently emerges, policy makers find it difficult to justify their attempted deference to science.

On the other hand, officials in most jurisdictions are keen to maximise the scope for their exercise of autonomous discretion when deciding which risks to assess and the benchmarks of acceptability. Overt exercising of discretion is unavoidable when the uncertainties in the science, and the non-scientific aspects of policy-making are explicitly acknowledged.

The judgements of the WTO Dispute Panel and Appellate Body in the beef hormones case implicitly set some minimum benchmarks that need to be met by any lawful measure ostensibly intended to control risks arising from food and agricultural products and processes. These requirements are as procedural as they are substantive. The policy measure has to be 'based on' a scientific risk assessment and that assessment must focus on the risks that the measure aims to control. Risk assessments, on which those measures are based, can however diverge from mainstream or dominant views, but they must be the products of systematic deliberation by professional scientists with relevant expertise, or what the WTO Appellate Body called 'qualified and respected sources'. Those risk assessments may, moreover, sustain a trade-restrictive measure even without demonstrable proof of hazard or risk but, in such cases, the risk assessment has to provide evidence of more than just ignorance: there needs to be some prima facie 
evidence of some possible adverse effect. However that evidence need not be overwhelming, let alone conclusive. At each stage precaution may legitimately be exercised.

Unless there are prior agreements, however, about which kinds of effects are within the scope of the risk assessment and which are deemed to be significantly adverse, and consequently which scientific questions the risk assessors need to address, there will always remain scope for persistent and irresolvable disputes about regulatory measures.

Jurisdictions could move towards arrangements to meet those conditions if risk appraisal and decision-making procedures learned to make explicit the upstream framing assumptions with which they operate, so that they can become transparently accountable and democratically legitimate 


\section{Appendix I: lists of interviewees}

\section{US Interviewees}

Regulatory \& advisory

Senior Official, Division of Human Food Safety, FDA Center for Veterinary Medicine

Senior Official, Center for Veterinary Medicine

Senior Official, a former Director of CVM

Senior Official, a former member of the FDA's Food Advisory Committee

Senior officials, Biopesticide and Pollution Prevention Division, EPA Office of Pesticide

Programs

Industry

Senior Official, Bio-Industry Organization

Senior Official, Monsanto, Regulatory Affairs

Senior Official, of law firm acted as legal consultant for the leading agricultural trade association

\section{$\underline{\mathrm{NGOs}}$}

Senior Official, Center for Food Safety (CFS)

Senior Official, policy officers, Consumers Union (CU)

Senior Official, Union of Concerned Scientists (UCS)

\section{UK Interviewees}

Regulatory \& advisory

Official, Department of the Environment, Biotechnology Division

Official, Veterinary Medicines Directorate, Ministry of Agriculture

Two members of the Advisory Committee on the Release to the Environment, and one former member of that Committee

Two scientists, members of the Veterinary Products Committee

Two members of the Veterinary Products Committee

Former member of Advisory Committee on the Release to the Environment

Three members of the Agriculture and Environment Biotechnology Commission

A former members of the Joint Expert Committee on Food Additives

Industry

Two officials, National Farmers Union

NGOs

Two representatives of consumer organisations

\section{French Interviewees}

Regulatory \& advisory

Senior Officials, Prime Minister's Cabinet Office (agriculture \& environment)

Officials, Ministry of Agriculture, Food Safety Directorate

Official, Ministry of Environment

Expert advisors, AFSSA (Food Safety Agency)

Industry

Official, Organibio (Federation of Biotech Cies)

NGO

Official, Consumer NGO 


\section{Austrian Interviewees}

Regulatory \& advisory

Two senior officials, Federal Ministry of Social Security and Generations

Two senior officials, Federal Ministry of Agriculture and Forestry, Environment, and Water Management

Two senior officials, Federal Ministry of Economic Affairs and Labour

Advisory (scientific)

Senior scientific advisor, Federal Environment Agency

Senior scientific advisor, Austrian Research Centre Seibersdorf

Senior scientific advisor, Institute of Biochemistry, University of Vienna

Industry

Senior advisor, Institute of Molecular Pathology and Federal Chamber of Commerce

Senior official, Conference of the Presidents of Agricultural Chambers

Two senior officials, Federal Chamber of Labour

\section{NGOs}

Senior officials, Global 2000/Friends of the Earth Austria

Senior official, Greenpeace Austria

\section{European Commission Interviewees}

Officials, DG Sanco, DG Environment, DG Trade, DG Research

Officials, Consumer NGO \& Environmental NGOs

Official, EuropaBio (the European Association for Bioindustries)

Official, FEDESA (European Federation of Animal Health)

Official, CIAA (Confederation of Food and Drink Industries of the EU)

Official, Multinational food and drink company

Official, Multinational biotech company

\section{World Trade Organisation Interviewees}

Officials, Agriculture and Commodities Division \& Trade and Environment Division

Official, Environmental and development NGO

Official, Environmental NGO 


\section{Appendix II}

\section{Definitional aspects}

1a. What general assumptions about the role of science in policy-making are being made?

1b. What assumptions are being made about the nature of decisions about what counts as 'harm' or 'risk'? How is the scope of risk assessment being defined, and by whom?

1c. Are risk assessments represented, or understood as, absolute judgements or as relative ones, and if they are relative, what are the (explicit or implicit) benchmark by reference to which risks are compared? Are they consistent?

1d. Is full compliance with regulatory standards being assumed? Are risk assessments taking account the consequences of possible non-compliance?

1e. Are uncertainties acknowledged? How are the uncertainties understood? To what extent are scientific uncertainties and ignorance recognised?

\section{Evidential aspects}

2a. How much of which kinds of evidence are necessary, acceptable and/or sufficient for risk assessments to support particular kinds of judgements i.e. claims of risk or safety?

$2 \mathrm{~b}$. How is the evidence from both positive and negative studies handled? To what extent are the various jurisdictions explicitly addressing the possibility of accepting false positives and false negatives?

\section{Understandings of precaution}

How far can regulatory differences be explained as a consequence of different interpretations of the nature, role, scope and application of the Precautionary Principle? 


\section{References}

${ }^{1}$ A Stirling, 'Risk at a turning point', Journal of Risk Research, Vol. 1 No 2. 1998, pp. 97-110

${ }^{2}$ European Commission's Scientific Committee on Veterinary Measures relating to Public Health, 1999, Tables A4 and A5

${ }^{3}$ European Commission's Scientific Committee on Veterinary Measures relating to Public Health, Report on Public Health Aspects of the Use of Bovine Somatotrophin, 15-16 March 1999; European Commission's Scientific Committee on Animal Health and Animal Welfare, Report on Animal Welfare Aspects of the Use of Bovine Somatotrophin, 10 March 1999

${ }^{4}$ T B Mepham, 'Public health implications of bovine somatotropin use in dairying: discussion paper', Journal of the Royal Society of Medicine, Dec 1992, Vol 85 pp. 736-739; E. Millstone et al, 'Plagiarism or protecting public health?', Nature, 20 Oct 1994, Vol. 371, No 6499, pp. 647-8

${ }^{5}$ Board on Agriculture and Natural Resources, US National Research Council, Environmental Effects of Transgenic Plants: The Scope and Adequacy of Regulation Committee on Environmental Impacts Associated with Commercialization of Transgenic Plants, National Academy Press, April 2002 available at: http://books.nap.edu/books/0309082633/html/1.html\#pagetop, page 8

${ }^{6}$ Hilbeck, A., Baumgartner, M., Fried, P.M. \& Bigler, F. (1998) Effects of transgenic Bt corn fed prey on mortality and development time of immature Chrysoperla carnea Neuroptera: Chrysopidae.

Environmental Entomology 27: 460-487; Losey, J.E., Rayor, L.S., Carter, M.E., 1999, 'Transgenic pollen harms monarch larvae', Nature Vol. 399, p. 241 ff

${ }^{7} \mathrm{P}$ Weingart, 'Scientific Expertise and political accountability: paradoxes of science in politics', Science and Public Policy, Vol. 26 No 3, June 1999, pp. 151-161; A Trichopoulou et al, European Policy on Food Safety, report to the European Parliament's Scientific and Technological Options Assessment Programme (STOA), June 2000, European Parliament document number PE 292.026/Fin. St. Available at http://www.europarl.eu.int/dg4/stoa/en/publi/default.htm

${ }^{8}$ US Food and Drug Administration, Precaution in U.S. Food Safety Decisionmaking, Annex II to the United States' National Food Safety System Paper, 3 March 2000, available at:

http:///www.foodsafety.gov/ fsg/fssyst 4. html, para A1, p. 3

${ }^{9}$ Cohen, R. (1998) Milk: The Deadly Poison, Argus Publishing, Englewood Cliffs, New Jersey, 1997

${ }^{10}$ U.S. Government submission to the Committee on General Principles of the Codex Alimentarius Commission for the Committee's April 10-14, 2000 meeting, in European Commission Communication on Precaution, General Point 5, available at http://www.fsis.usda.gov/OA/Codex/confpaper.htm

${ }^{11}$ van Leeuwen, CJ in "Risk Assessment of Chemicals: an Introduction" (Ed. Van Leeuwen and Hermens), Kluwer Academic Publishers, Dordrecht, 1995

${ }^{12}$ Advisory Committee on Releases to the Environment: Sub-group on Wider Biodiversity Issues. Notes of meeting - 10th January 2000. http://www.environment.detr.gov.uk/acre/biodiversity/000110m.htm

${ }^{13}$ Weinberg A. (1972) 'Science and Trans-Science', Minerva, Vol. 10, pp. 209-222; U.S. Government submission to the Committee on General Principles of the Codex Alimentarius Commission for the committee's April 10-14, 2000

${ }^{14}$ In practice the phrase 'other legitimate factors' is being interpreted in two main ways. One version is to see them as purely non-scientific considerations, while another slightly more nuanced view assumes that scientific and considerations, that are not internal to assessments of risk, may nonetheless contribute to the class of other factors that are nonetheless have a legitimate bearing on risk management policymaking. EC Regulation 178/2002, Laying down the general principles and requirements of food law, establishing the European Food Safety Authority, preamble para 19. indicates for example that a 
“....risk assessment alone cannot, in some cases, provide all the information on which a risk management decisions should be based, and that others factors relevant to the matter under considerations including societal, economic, traditional, ethical and environmental factors and the feasibility of controls."

${ }^{15}$ The European Commission's Communication on Precaution, European Commission (2000). Communication from the Commission on the Precautionary Principle, $\operatorname{COM}(2000) 1,2$ February 2000; available at http://europa.eu.int/comm/dgs/health consumer/library/pub/pub07 en.pdf; A similar perspective, but from the USA, can be found in G Goh and A R Ziegler, 'Implications of recent SPS dispute settlement cases', in K Anderson, C McRae, and D Wilson (eds), The Economics of Quarantine and the SPS Agreement, Centre for International Economic Studies and AFFA Biosecurity Australia, Canberra, 2001, pp. 75-105

${ }^{16}$ R. May, The Use of Scientific Advice in Policy Making, Office of Science and Technology, 2000, see http://www.dti.gov.uk/ost/ostbusiness/index policy making_old.htm

${ }^{17}$ R. May, The Use of Scientific Advice in Policy Making, Office of Science and Technology, 2000, p.9

${ }^{18}$ van Leeuwen, op. cit. page 6

${ }^{19}$ Codex Alimentarius Commission, Procedural Manual, eleventh edition, 2000, FAO and WHO, Appendix pp. 180-181

${ }^{20}$ Veterinary medicines are anomalous in this context however because for historical reasons AFSSA is responsible for both the risk assessment and risk management aspects of veterinary medicines. In all other relevant policy domains, however, AFSSA is supposed to give science-based advice, but not to decide policy.

${ }^{21}$ Southwood, R. (1998) Witness Statement No 1 to BSE Inquiry, para. 25, in Phillips et al 2000 The BSE Inquiry: Report: evidence and supporting papers of the Inquiry into the emergence and identification of Bovine Spongiform Encephalopathy (BSE) and variant Creutzfeldt-Jakob Disease (vCJD) and the action taken in response to it up to 20 March 1996. The Stationery Office, London

${ }^{22}$ Kourilsky, P. and Viney, G. (2000) Le Principe de Précaution: Rapport au Premier Ministre, Odile Jacob: Paris, pp. 69-72. http://www.ladocfrancaise.gouv.fr/

${ }^{23}$ Health and Safety Executive, Reducing Risks, Protecting People, 13 December 2001, p. 11 see http://www.hse.gov.uk/press/e01229.htm

${ }^{24}$ Codex Alimentarius Commission, Committee on General Principles, Alinorm 03/41, July 2003, p. 126, paras. 13-16

${ }^{25}$ DG-JRC \& Research (2000) 'Science and Governance in a Knowledge Society: The Challenge for Europe', 16-17 October, conference conclusions, http://www.jrc.es/sci-gov

${ }^{26}$ http://www.aebc.gov.uk/aebc/aboutus.html

${ }^{27}$ SAP (2000) Characterization and Non-Target Organism Data Requirements for Protein PlantPesticides, SAP Report No. 1999-06, from FIFRA Scientific Advisory Panel Meeting, December 1999, http://www.epa.gov/scipoly/sap/1999/\#december

${ }^{28}$ Board on Agriculture and Natural Resources, US National Research Council, Environmental Effects of Transgenic Plants: The Scope and Adequacy of Regulation Committee on Environmental Impacts Associated with Commercialization of Transgenic Plants, National Academy Press, April 2002 available at: http://books.nap.edu/books/0309082633/html/1.html\#pagetop

${ }^{29}$ J L Fox, 'National Academy panel urges USDA to toughen reviews of transgenic plants', Nature Biotechnology, Vol. 20, April 2002, p. 323-4 
${ }^{30}$ Board on Agriculture and Natural Resources, US National Research Council, Environmental Effects of Transgenic Plants: The Scope and Adequacy of Regulation Committee on Environmental Impacts Associated with Commercialization of Transgenic Plants, National Academy Press, April 2002, p. 4

${ }^{31}$ Board on Agriculture and Natural Resources, US National Research Council, Environmental Effects of Transgenic Plants: The Scope and Adequacy of Regulation Committee on Environmental Impacts Associated with Commercialization of Transgenic Plants, National Academy Press, April 2002, p. 4

${ }^{32}$ L Levidow, S Carr \& D Wield, 'Genetically modified crops in the European Union: regulatory conflicts as precautionary opportunities', Journal of Risk Research, Vol 3 No 3, July 2000, pp. 189 208; H Torgersen \& F Seifert, 'Austria: precautionary blockage of agricultural biotechnology', Journal of Risk Research, Vol 3 No 3, July 2000, pp. 209 - 217; A Roy \& P-B Joly, 'France: broadening precautionary expertise?' Journal of Risk Research, Vol 3 No 3, July 2000, pp. 247 - 254; L Levidow \& S Carr, 'UK: precautionary commercialization?', Journal of Risk Research, Vol 3 No 3, July 2000, pp. $261-270$

${ }^{33}$ Board on Agriculture and Natural Resources, US National Research Council, Environmental Effects of Transgenic Plants: The Scope and Adequacy of Regulation Committee on Environmental Impacts Associated with Commercialization of Transgenic Plants, National Academy Press, April 2002 available at: http://books.nap.edu/books/0309082633/html/1.html\#pagetop, pp. 10-11

${ }^{34}$ Hilbeck, A., Baumgartner, M., Fried, P.M., Bigler, F., 1998a, 'Effects of transgenic Bacillus thuringiensis corn-fed prey on mortality and development time of immature Chrysoperia carnea (Neuroptera: Chrysopidae)', Environmental Entomology, Vol. 27, 2, 480 - 487; Hilbeck, A., Moar W.J., Pusztai-Carey, M. Filippini, A., Bigler, F., 1998b, 'Toxicity of Bacillus thuringiensis CryIA(b)-toxin to the predator Chrysoperia carnea (Neuroptera: Chrysopidae) using diet incorporated bioassays', Environmental Entomology, Vol. 27, No. 4, pp. 1255 - 1263); Losey, J.E., Rayor, L.S., Carter, M.E., 1999, 'Transgenic pollen harms monarch larvae', Nature, Vol. 399, p. 241 ff; UCS (2000) 'Bt-Corn Pollen from Iowa Fields Kills Monarch Caterpillars', Union of Concerned Scientists, http://www.ucsusa.org/food/0biotechnology.html

${ }^{35}$ EcoStrat (2000) Hilbeck A, Meier M \& Raps A, Review on Non-Target Organisms and Bt Plants, commissioned by Greenpeace International, Amsterdam, available at: http://www.greenpeaceusa.org/media/press releases/gmo-report-complete.pdf

${ }^{36}$ Department of the Environment, Transport and the Regions, Guidance on the Assessment of Risk to Wider Biodiversity from Proposed Cultivation of GM Crops, 15 March 2000, http://www.environment.detr.gov.uk/consult/biodiversity/risk/index.htm

${ }^{37}$ T B Mepham, 'Public health implications of bovine somatotropin use in dairying', Journal of the Royal Society of Medicine, Vol 85, Dec 1992, pp. 736-739

38 EcoStrat (2000) Hilbeck A, Meier M \& Raps A, Review on Non-Target Organisms and Bt Plants, commissioned by Greenpeace International, Amsterdam, available at: http://www.greenpeaceusa.org/media/press_releases/gmo-report-complete.pdf

${ }^{39}$ US EPA Scientific Advisory Panel, Bt Plant-Pesticides Risk and Benefit Assessments, SAP Report No. 2000-07, from FIFRA Scientific Advisory Panel Meeting, October 2000, http://www.epa.gov/scipoly/sap/2000/\#october, p. 57

${ }^{40}$ US EPA Scientific Advisory Panel, Bt Plant-Pesticides Risk and Benefit Assessments, SAP Report No. 2000-07, from FIFRA Scientific Advisory Panel Meeting, October 2000, http://www.epa.gov/scipoly/sap/2000/\#october, p. 54

${ }^{41}$ Advisory Committee pn Releases To The Environment, Advice For The Secretary of State, 22 July 1998, Significance Of New Research On Effect Of Toxin On Lacewings,

http://www.environment.detr.gov.uk/acre/advice02.htm 
${ }^{42}$ Advisory Committee on Releases to the Environment, A Report on a Paper Concerning the Effect of Genetically Modified Bt Maize on Monarch Butterflies, 29 September 2000, http://www.environment.detr.gov.uk/acre/000929m.htm

${ }^{43}$ US EPA, Scientific Advisory Panel, 'Bt Plant-Pesticides Risk and Benefit Assessments', SAP Report No. 2000-07, from FIFRA, Scientific Advisory Panel Meeting, October 2000, http://www.epa.gov/scipoly/sap/2000/\#october p. 59

${ }^{44}$ US National Research Council (2000) Genetically Modified Pest-Protected Plants: Science and Regulation. Washington, DC: National Academy Press, pp. 11-12

${ }^{45}$ US National Research Council (2000) Genetically Modified Pest-Protected Plants: Science and Regulation. Washington, DC: National Academy Press, p. 80

46 'Bt Plant-Pesticides Risk and Benefit Assessments', SAP Report No. 2000-07, from FIFRA Scientific Advisory Panel Meeting, October 2000, http://www.epa.gov/scipoly/sap/2000/\#october, p.59

${ }^{47}$ Risk Assessment for Release and Marketing of GMOs in the European Union, Paper by the UK Joint Regulatory Authority and Secretariat to ACRE, August 2000 http://www.environment.detr.gov.uk/acre/background/risk/index.htm

${ }^{48}$ Department of the Environment, Transport and the Regions, Guidance on the Assessment of Risk to Wider Biodiversity from Proposed Cultivation of GM Crops, 15 March 2000, http://www.environment.detr.gov.uk/consult/biodiversity/risk/index.htm

${ }^{49}$ BSE was not one of our case studies, but it was a policy challenge to which many interviewees made reference.

${ }^{50}$ Hansen, M., et al. 'Potential Public Health Impacts of the Use of rBST in Dairy Production', prepared for a scientific review by JECFA, Yonkers, NY: Consumers Union, 1997, p. 2

http://www.consumersunion.org/food/bgh-Codex.htm

\section{List of abbreviations}


ACRE - UK's Advisory Committee on the Release to the Environment AFSSA - Agence Française de la Sécurité Sanitaire des Aliments AEBC - Agriculture and Environment Biotechnology Commission APHIS - US government's Animal and Plant Health Inspection Service BAP - Biodiversity Action Plans Codex - Codex Alimentarius Commission DETR - the Department of Environment, Transport and the Regions ECB - European Corn Borer EU - European Union

GM - Genetically Modified

ICM - Integrated Crop Management

JECFA - Joint FAO/WHO Expert Committee on Food Additives

NRC - US National Research Council

OLFs - other legitimate factors

SAP - Scientific Advisory Panel of the US EPA

SPS - Sanitary and Phytosanitary Agreement

SCAHAW - Scientific Committee on Animal Health and Animal Welfare

SCP - European Commission's Scientific Committee on Plants

SCVMPH - Scientific Committee on Veterinary Measures relating to Public Health

SEAC - Spongiform Encephalopathy Advisory Committee

RBST - recombinant Bovine Somatotropin

UK - United Kingdom

USA - United States of America 
WTO - World Trade Organisation 